NASA Technical Memorandum 106240

AIAA-93-1847

\title{
3-D Viscous Flow CFD Analysis of the Propeller Effect on an Advanced Ducted Propeller Subsonic Inlet
}

Chanthy Iek and Donald R. Boldman

Lewis Research Center

Cleveland, Ohio

and

Mounir Ibrahim

Cleveland State University

Cleveland, Ohio

Prepared for the

29th Joint Propulsion Conference and Exhibit

cosponsored by the AIAA, SAE, ASME, and ASEE

Monterey, California, June 28-30, 1993 


\title{
3-D Viscous Flow CFD Analysis of the Propeller Effect on an Advanced Ducted Propeller Subsonic Inlet
}

\author{
Chanthy Iek ${ }^{1}$, Donald R. Boldman ${ }^{2}$ \\ National Aeronautics and Space Administration \\ Lewis Research Center \\ Cleveland, Ohio 44135 \\ Mounir Ibrahim ${ }^{3}$ \\ Cleveland State University \\ Cleveland, Ohio 44115
}

\begin{abstract}
$\underline{\text { Abstract }}$
A time marching Navier-Stokes code called PARC3D was used to study the 3-D viscous flow associated with an advanced ducted propeller (ADP) subsonic inlet at take-off operating conditions. At a free stream Mach number of 0.2 , experimental data for the inlet-with-propeller test model indicated that the airflow was attached on the cowl windward lip at an angle of attack of $25^{\circ}$, became unstable at $29^{\circ}$, and separated at $30^{\circ}$. An experimental study with a similar inlet and with no propeller (through-flow) indicated that flow separation occurred at an angle of attack a few degrees below the value observed when the inlet was tested with the propeller. This tends to indicate that the propeller exerts a favorable effect on the inlet performance. During the through-flow experiment a stationary blockage device was used to successfully simulate the propeller effect on the inlet flow field at angles of attack. In the present numerical study, this flow blockage was modeled via a PARC3D computational boundary condition (BC) called the screen $B C$. The principle formulation of this $\mathrm{BC}$ was based on the one-and-half dimension propeller was used.

\section{Nomenclature}

A flow area, $\mathrm{m}^{2}$

BC boundary condition

D diameter, $m$

$\mathrm{h} \quad$ enthalpy per unit mass, $\mathrm{J} / \mathrm{kg}$

$\mathrm{L}$ inlet length, $\mathrm{m}$

M Mach number

$\mathrm{P}$ total pressure, $\mathrm{Pa}\left(\mathrm{N} / \mathrm{m}^{2}\right)$

$\mathrm{p}$ static pressure, $\mathrm{Pa}\left(\mathrm{N} / \mathrm{m}^{2}\right)$

prop. propeller

t static temperature, ${ }^{\circ} \mathrm{K}$

W mass flow rate $(\mathrm{kg} / \mathrm{sec})$
\end{abstract}

actuator disk theory. This screen BC was applied at the inlet propeller face station of the computational grid. Numerical results were obtained with and without the screen $\mathrm{BC}$. The application of the screen $B C$ in this numerical study provided results which are similar to the results of past experimental efforts in which either the blockage device or the

1 Aerospace Research Engineer Member of AIAA

2 Aerospace Research Engineer Assoc. Fellow AIAA

3 Assoc. Professor

Member of AIAA 


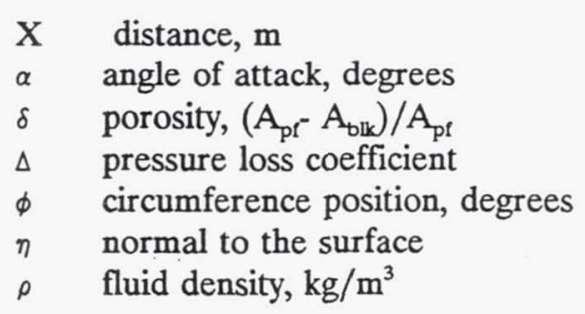

Subscripts:

$\begin{array}{ll}0 & \text { free stream } \\ \text { blk } & \text { blockage } \\ \text { c } & \text { captured } \\ \text { eff } & \text { effective } \\ \text { flx } & \text { flux } \\ \text { loc } & \text { local value on surface } \\ \text { pf } & \text { propeller face } \\ \text { pk } & \text { peak }\end{array}$

Introduction

One of the critical flow characteristics associated with a subsonic inlet is the onset of a flow separation during a steep climb at take-off operating conditions. Flow separation presents a major concern for a subsonic inlet designer. Up to the present time, the angle of attack $(\alpha)$ at which the inlet flow separation would occur has been generally determined by relying on experimental studies. Design and development then follow with a provision of off-design performance margin of safety by increasing the thickness of the inlet cowl lip. However, a thick lip would increase the inlet weight and at cruise it would develop high drag and result in a reduction of the critical flight Mach number for the inlet beyond which the divergent drag rise would occur. So, it is desirable to keep the inlet cowl lip as thin as possible for cruise and as thick as necessary to keep the flow attached for take-off. In order to achieve an optimized inlet cowl design, initially one needs to determine the value of $\alpha$ that induces the onset of flow separation associated with an existing inlet geometry. Then, the cowl geometry can be altered accordingly until the optimized thickness is attained. However, problems that arise in this design procedure are not simple since predicting subsonic inlet flow separation is still a challenge in the field of CFD study.

The CFD community has completed several numerical studies of flows associated with through- flow and powered nacelles with ducted propellers for take-off and cruise operating conditions. Wie et al. [1] recently performed an inlet nacelle design/analysis study. This study explored the feasibility of designing a low drag hybrid-laminar-flow nacelle by using a combination of an inverse Euler calculation and a 2-D flow prediction of laminarturbulent boundary-layer transition. Valarezo [2] performed an analysis of a ducted propeller using a lower-order velocity panel method to study a circulation and pressure loading on propeller blades for different gap sizes between blade tip and the shroud. Mendenhall and Spangler [3 \& 4$]$ conducted a numerical study of a ducted fan performance by using a potential flow method to estimate the aerodynamics at various $\alpha$ 's. Chen et al. [5], Uenishi et al. [6], and Hirose et al. [7] applied Euler analyses to flow-through and powered nacelles including the fan cowl, centerbody, and fan exit for axial flow and moderate values of $\alpha$ 's for take-off and cruise flight conditions. For take-off conditions, Chen analyzed a non-separated flow condition associated with a powered nacelle at a free stream Mach number $\left(\mathrm{M}_{0}\right)$ of 0.27 and an angle of attack of $25^{\circ}$. Nakahashi [8] developed a hybrid method of finite difference (FDM) and finite element (FEM) to solve the Reynolds-averaged Navier-Stokes (RANS) equations by FDM and Euler equations by FEM. This hybrid method was applied to predict 3-D non-separated viscous flows associated with an inlet nacelle for take-off and cruise conditions. The validity of this hybrid method was assessed based on the computational results only. Srivastava [9] applied a hybrid implicitexplicit unsteady scheme to solve the Euler equations to allow prediction of the aeroelastic characteristics of a ducted propeller at cruise. Hall and Delany [10] developed a 3-D Euler-based computer code to predict flow characteristics associated with a single-stage ducted propeller for axial and high $\alpha$ free stream flows. Boldman et al. [11] applied a panel method with a built-in compressibility correction to evaluate several ducted propeller inlets for take-off conditions. By employing an empirical method based on the inlet cowl peak Mach number $\left(\mathrm{M}_{\mathrm{pk}}\right)$, the results could provide an indication of the angle of attack at which the inlet flow would separate. The panel method did not account for the propeller effect; however, without separation the comparison shows that the potential flow prediction of inlet static pressures agrees favorably with the ducted propeller inlet test 
data.

Experimental Background

Potential flow and Euler analyses are generally fast for computer turn-around time solutions. Both are capable of providing reasonable flow predictions but are limited to certain flow conditions. Potential flow calculations are limited to a subsonic nonseparated flow. Euler calculations can handle both subsonic and supersonic flows but are limited to a non-separated flow.

As part of the advanced ducted propeller (ADP) research program, NASA Lewis Research Center (LeRC) and Pratt and Whitney (P\&W) conducted experimental studies of the aerodynamics associated with several ADP inlet test models with and without a propeller. The test data from these studies [11] and [12] show that without the propeller the inlet flow separated at an $\alpha$ value of a few degrees lower than when the inlet was tested with a propeller. For a ducted propeller the problems associated with the inlet design become more complicated as a result of the propeller effect on the inlet internal flow performance. The interaction between a rotating propeller and a flow stream is very complex. As far as a ducted propeller inlet design and analysis are concerned, it is important to understand the propeller-inlet flow interaction and the net results on the overall system aerodynamic performance. That understanding could help to advance the design and analysis procedures to take a full accountability of this propeller-inlet flow interaction, thus providing a highly efficient system.

The present study analyzes an ADP inlet that was tested at the NASA LeRC in the $9 \times 15$-Foot Low Speed Wind Tunnel. The study made use of an existing general purpose flow solver called the PARC3D code which solve the 3-D RANS equations. The primary interest of this study was to apply the code to predict the ADP inlet aerodynamic characteristics at take-off for angles of attack that result in three flow conditions which include attached flow, unstable flow (just about to separate), and separated flow. Grid modeling of the ADP inlet did not include the actual propeller geometry. The propeller effect in this study was accounted for by using a computational BC which simulates a blockage effect at the propeller face.

\section{ADP Simulator - with Propeller}

In 1990, NASA LeRC and P\&W jointly conducted an experimental research study to develop design technology for a low noise/low drag ADP propulsion system. An ADP simulator was installed in the NASA LeRC's 9 x 15-Foot Low Speed Wind Tunnel as shown in figure 1 . The test data were taken for a nominal $\mathrm{M}_{0}$ of 0.2 , $\alpha^{\text {'s }}$ of $0^{\circ}$ to $35^{\circ}$, and for propeller speeds from 7,500 to 12,000 RPM. The inlet captured mass flow rates $\left(W_{c}\right)$ ranged from 14.06 to $21.12 \mathrm{~kg} / \mathrm{sec}$.

The ADP inlet shown in figure 1 was tested with and without the installation of four total pressure recovery rakes. The test data shows that the removal of these rakes resulted in inlet flow separation at an $\alpha$ of about two degrees lower than observed when the rakes were installed. For the analysis, the computational grid did not model these total pressure recovery rakes so it would be appropriate to compare the computational results with the ADP experimental data that were obtained without the installation of these rakes. Figure 2 shows schematics of the ADP inlet model instrumentation without these rakes. Two axial rows of static pressure taps are located on the inlet cowl windward side $\left(\phi=0^{\circ}\right)$ and on the inlet cowl leeward side $\left(\phi=180^{\circ}\right)$. A set of pressure taps was located circumferentially around the inlet and at a location $0.5 \mathrm{~cm}$ upstream of the propeller face. Instrumentation was not installed on the center body because it rotated with the propeller during testing.

\section{Through-Flow and Propeller Simulation}

In 1991 NASA LeRC and P\&W conducted an experimental study of an inlet without a propeller (through-flow nacelle). The effect of the propeller on the ADP inlet could be determined by comparison of the data from the through-flow program with the data from the 1990 test of the inlet with a propeller installed. The test techniques to simulate this propeller effect were investigated. This experimental test program was conducted in the United Technologies Research Center's 10 x 15 Foot Subsonic Wind Tunnel. The inlet used in this experimental study is called the baseline inlet (Fig. 
3). The method that was used to simulate the propeller effect was to partially block the inlet flow by using a stationary blockage device that was installed at the propeller face. The device was made of 25 tapered rods as shown in figure 4 . The inlet that was analyzed in the numerical study of this paper (Fig. 1) is called the midlength inlet. Schematics in figure 5 show a comparison of the two inlets. They have the same centerbody and a similar cowl geometry with same propeller face diameter $\left(\mathrm{D}_{\mathrm{p} t}\right)$ but the cowl leading edge of the baseline inlet is about $5.0 \mathrm{~cm}$ longer than that of the midlength inlet. The inlet-with-propeller (ADP) experimental data reported in [11] shows that qualitatively the two inlets have very similar flow performance characteristics.

Figure 6 shows the through-flow static pressure distributions on the cowl windward side of this baseline inlet at $\mathrm{M}_{0}=0.2$ and $\mathrm{W}_{\mathrm{c}}=17.41 \mathrm{~kg} / \mathrm{sec}$. At $\alpha=25^{\circ}$, the inlet flow was attached (Fig. 6(a)) and at $\alpha=26^{\circ}$ the flow was fully separated (Fig. $6(b))$. The attached flow is identified by a high rate of static pressure change or suction around the cowl lip producing a low minimum peak static pressure at the highlight. The separated flow in this case is an inlet lip separation resulting in a relatively flat static pressure distribution from the highlight. With the inlet lip separated, there is little or no diffusion as the flow moves downstream.

Through-flow data for the baseline inlet shows a separation at $\alpha=26^{\circ}$, but test data for the same inlet when tested with a propeller indicated that separation occurred at $\alpha=30^{\circ}$. This difference could be attributed to the effect of the propeller. A stationary blockage device (Fig. 5) was installed at the propeller face. This device simulated the aerodynamic effect of the propeller by partially blocking the inlet flow.

Figure 7 shows a comparison of static pressure distributions from the baseline inlet when tested with the blockage device and with the propeller for $\mathrm{M}_{0}=0.2$ and $\mathrm{W}_{\mathrm{c}}=17.41 \mathrm{~kg} / \mathrm{sec}$. At $\alpha=28^{\circ}$ (Fig. $7(a))$ the static pressure distributions are nearly the same which indicates that the effect of the blockage device was similar to that of the propeller. At $\alpha=$ $29^{\circ}$ (Fig. 7(b)), the static pressure distribution from the inlet with the blockage device shows the flow was separated while the data for the inlet with the propeller shows that the flow was still attached.
This indicates that the inlet-with-propeller performance was at a stall or unstable condition from a slight upward shift of the minimum static pressure as the angle of attack increased from $28^{\circ}$ to $29^{\circ}$. At $\alpha=30^{\circ}$ both static pressure distributions are similar and indicate that the inlet flow was separated. This comparison shows that the stationary blockage device was capable of simulating the effect of the propeller to within one degree of inlet separation angle of attack. A comparison with the through-flow test results (Fig. 6) shows that either the propeller or the stationary blockage device was capable of enhancing the inlet performance by increasing the flow separation angle of attack a few degrees higher than that associated with the inlet through-flow. The physics of the inlet flow interaction with the propeller or with the blockage device is not well understood at this time. Physically the stationary rods induced a blockage effect on the inlet mainstream flow. Nonetheless, the positive contribution of the propeller to the angle-of-attack capability could be significant for an advanced subsonic inlet design where a compromise needs to be made between a thin cowl lip to achieve low drag and a thick cowl lip to prevent lip separation. This data base suggests that the propeller effect can provide a safety margin for a ducted propeller inlet at take-off operating conditions.

\section{Computations}

\section{$\underline{\text { PARC3D Code }}$}

The PARC3D code was selected for this numerical study. It is a 3-D, multi-block Reynolds averaged Navier-Stokes (RANS) solver. It utilizes the central differencing scheme on a generalized curvilinear coordinate system. The turbulence model used in the code is the Baldwin-Lomax model. An essential feature of the PARC3D code is its capability to compute flows about complex geometries. Computational boundary conditions can be specified on any portion of the grid surfaces. The code incorporates a semi-automatic time-step control function which helps to maintain the stability for the flow solution being calculated. Additional details about the code can be found in [13]. 


\section{Computational Grid}

A general purpose CFD grid generating tool called GRIDGEN [14] was utilized to generate the multiblock grid for this study. Figure 8(a) shows a 2-D multi-block H-grid, a block of $\mathrm{C}$-grid, and a section of the H-grid with embedded C-grid (HC-grid). The HC-grid was the grid topology used in this numerical study. The reason for employing the grid-embedding method was that the $\mathrm{H}$-grid alone would induce a computational error in the flow field near the inlet highlight as discussed in [15]. This error was eliminated by embedding a C-grid block around the inlet cowl. The grid size for each block is shown in terms of a 2-D matrix with the first and second digits representing the number of grid points along the axial and transverse directions, respectively. Grid block lines were generated using a combination of the Bazier's curve fit and the transfinite interpolation. The internal grid lines and clustering at the wall boundaries were generated using the algebraic solver followed by an elliptic solver to smooth the grid lines as well as to rearrange the internal grid spacing. The 3-D grid shown in figure $8(\mathrm{~b})$ was made by rotating the $2-\mathrm{D}$ grid fifty increments circumferentially through $180^{\circ}$. The total number of grid points in the 3-D HC-grid is $7.6 \times 10^{5}$.

\section{Computational Boundary Conditions}

Figure 9 shows computational BC's applied at various sections of the grid. The flow field throughout the computational domain was viscous. The external portion of the flow field terminated at the nacelle trailing edge; therefore, the calculation did not account for the effect of the plume aft of the nacelle. According to an analysis study by Uenishi [6], the effect of the plume propagates upstream but not far enough to influence the inlet internal flow performance. The nacelle surrounding flow field was calculated using the computational free-stream BC. At the inlet nacelle surface, a noslip BC was specified. The screen $B C$ and the mass $B C$ were specified at the inlet propeller face and at the nacelle exit, respectively. Mathematical formulations of free-stream, no-slip, and mass BC's are reported in [13].

\section{$\underline{\text { Screen BC }}$}

This BC was derived based on the 'one-and-half dimensions' actuator disk theory by Horlock [16]. It imposed a flow disturbance that behaves similar to a wire-mesh screen. When a flow passes through a screen there is some pressure loss. The magnitude of this loss depends on the flow velocity and the screen porosity. In order to compute the flow downstream of the screen, a pressure loss coefficient $(\Delta)$ was determined based on an experimental study by Pinker and Herbert [17]. The fundamental governing equations for the screen $\mathrm{BC}$ can be written

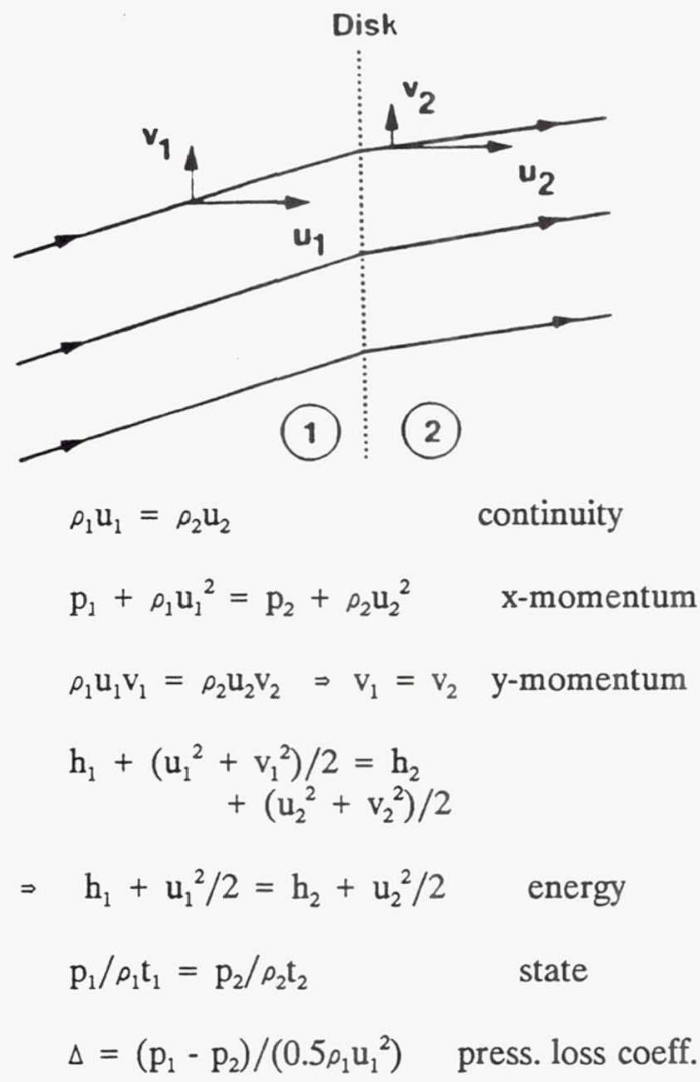

The pressure at the exit end of the screen cannot be determined analytically and is computed based on the value of pressure loss coefficient. The screen $\mathrm{BC}$ requires a specificaton of the screen porosity $(\delta)$. The value of $\delta$ is zero for 100 percent flow blockage and unity for zero percent flow blockage. From [12] based on a one-dimensional flow calculation, an amount of flow blockage which was effective in simulating the propeller effect induced a propeller face Mach number between 0.8 and 1.0. Based on this reference, a propeller face Mach number of 1.0 was selected to use in a determination of $\delta$. Using this Mach number and 
a $\mathrm{W}_{\mathrm{c}}$ of $21.12 \mathrm{~kg} / \mathrm{sec}$ would yield a value of 0.72 for $\delta$. Note that the propeller face Mach number of 1.0 was chosen simply for simplicity.

The screen BC is analogous to a passive blockage device that does not have any suction capacity to generate airflow through the inlet. In order to simulate a certain amount of mass flow a mass BC is needed downstream of the screen boundary. As shown in figure 9, the screen $B C$ was prescribed at the propeller face $B C 6$ and a mass $B C$ was at the inlet exit BC7. An inlet flow calculation using the screen $\mathrm{BC}$ at the propeller face means that a mass $\mathrm{BC}$ at the inlet exit is also required. An inlet flow calculation without the screen $\mathrm{BC}$ becomes simply a through-flow simulation.

\section{$\underline{\text { Results and Discussion }}$}

The PARC3D flow calculations were made using a computational grid of the ADP midlength inlet (Fig. 1) for a free stream Mach number $\left(M_{0}\right)$ of 0.2 , an inlet mass flow $\left(\mathrm{W}_{\mathrm{c}}\right)$ of $21.12 \mathrm{~kg} / \mathrm{sec}$, and angles of attack $(\alpha)$ of $25^{\circ}, 29^{\circ}$, and $30^{\circ}$. The selection of these three values of $\alpha$ was based on the experimental test data as shown in [11] which indicate that the inlet lip airflow was attached at $\alpha$ $=25^{\circ}$, unstable at $\alpha=29^{\circ}$, and separated at $\alpha=$ $30^{\circ}$. The flow prediction is evaluated by comparing the numerical results with the midlength inlet-withpropeller (ADP) experimental test data. The effect of the propeller was accounted for in this study by modeling the propeller blockage effect through the use of the computational screen $\mathrm{BC}$ specified at the propeller face. To generate a desired amount of airflow through the inlet, the computational mass BC was specified at the inlet exit plane. At $\alpha=25^{\circ}$ and $29^{\circ}$, the calculations were made with and without the screen BC. At $\alpha=30^{\circ}$, the calculation was made only with the screen $B C$.

\section{Angle of Attack of $25^{\circ}$ - No Separation}

Figure 10 shows the inlet flow Mach contours obtained from the PARC3D calculations with and without the screen BC at the inlet propeller face. The Mach contours in this figure for the inlet center plane show flow characteristics on the inlet windward (lower half) and leeward (upper half) sides for $\mathrm{M}_{0}=0.2, \alpha=25^{\circ}$, and $\mathrm{W}_{\mathrm{c}}=21.12 \mathrm{~kg} / \mathrm{sec}$. Without the screen BC (Fig. 10(a)), the cowl stagnation point on the leeward side is at the highlight and on the windward side is on the external flow surface just downstream of the highlight. On the cowl windward side near the highlight, the flow sensed a strong suction and expanded rapidly to a local peak Mach number $\left(\mathrm{M}_{\mathrm{pk}}\right)$ of 1.27 and then diffused downstream. On the leeward side near the cowl highlight, the flow expanded at a much slower rate than on the windward side. The boundary layer thickness on the cowl leeward side is thinner than on the cowl windward side at locations downstream of the highlight. The stagnation point on the center body is slightly off the center line; and the boundary layer thickness on the upper surface is similar to that on the lower surface. With the screen BC, the flow field in figure 10 (b) shows quantitatively similar characteristics to figure 10(a) upstream of the propeller face. A comparison of the Mach contours near the propeller face on figures 10 (a) and 10 (b) shows the effect of the screen $\mathrm{BC}$ on the inlet internal flow field. The use of the screen BC resulted in a redistribution of the flow field at the propeller face. Therefore, the screen BC apparently functioned like a blockage device at the propeller face. On the cowl windward side the screen BC generated a perturbation in the boundary layer which resulted in a reduction of the boundary layer thickness immediately upstream and downstream of the propeller face. On the cowl leeward side and on the center body, the screen BC also generated a similar perturbation; but the results are not obvious since the boundary layers are very thin.

Figure 11 shows two sets of circumferential static pressure contours obtained from the flow calculations with and without the screen BC. Each set contains the results for five inlet cross sections upstream of the propeller face. A comparison of these pressure contours shows the flow blockage effect that was induced by the screen $\mathrm{BC}$ only propagated a very short distance (about $3 \mathrm{~cm}$ ) upstream of the propeller face. Figure 12(a) shows circumferential static pressure contours from the flow calculation without the screen BC. The levels of static pressure lines vary in both radial and circumferential directions due to the 3-D flow phenomenon as a result of inlet operation at an angle of attack. With the screen BC that is shown in figure $12(\mathrm{~b})$, the circumferential pressure contours display a similar variation. A difference between the two figures is near the cowl and the 
centerbody surfaces on the inlet vertical centerline. With the screen BC, there is a large variation in static pressure. Without the screen $\mathrm{BC}$, only a slight variation in static pressure is apparent.

The screen BC should affect a ducted inlet flow in a manner similar to a wire-mesh screen. Reference 17 shows the pressure loss that is associated with a passage of airflow through a wiremesh screen. The amount of the loss is a function of $\delta$ and the approaching flow velocity. The screen BC used in this study was prescribed with a constant value of $\delta$. But the calculated flow velocity near the propeller face varies as indicated by static pressure contours in figure 12 . To evaluate the characteristics of the screen BC, total pressure contours in the streamwise direction were plotted for the inlet windward side. These contours plots, with and without screen BC, are shown in figure 13 . A comparison between figure 13(a) with figure 13(b) shows that the screen BC induced a total pressure loss in the flow field downstream of the propeller face. This loss varies from about 11 percent in the mainstream to a small loss in the boundary layer flow near the wall. The big loss in the mainstream is caused by a high approach flow velocity. The small loss near the wall is the result of a low boundary layer flow velocity. This evidence shows that the screen BC did, in fact, induce a similar effect to a wire-mesh screen [17].

Figure 14 shows a comparison of inlet cowl static pressure distributions between the ADP experimental data (with propeller) and computational results with and without using the screen BC for $\alpha=25^{\circ}$. On the windward side (Fig. 14(a)), the calculated pressure distribution without the screen $B C$ is practically the same as that resulting from the use of the screen $\mathrm{BC}$. The two predicted static pressure distributions agree favorably with the test data. On the leeward side (Fig. 14(b)), there is good agreement on the external cowl surface, but the predicted distributions on the internal cowl surface are slightly lower than the test data. The effect of the screen BC on the inlet flow, as shown in the Mach and pressure contour plots, did not have a significant impact on the cowl axial static pressure distribution upstream of the propeller face. Figure 15 shows a comparison of circumferential static pressure distributions on the cowl internal surface at $0.5 \mathrm{~cm}$ upstream of the propeller face between experimental data and computational results. Centerbody static pressure distributions with and without the screen $\mathrm{BC}$ are also shown in figure 15 . On the cowl side, the calculated distribution without the screen $B C$ is higher than when the screen $B C$ was used. Without the screen $\mathrm{BC}$ the results compare more favorably with the test data. The difference between the screen and no screen BC was due to the flow blockage effect of the screen BC. This blockage caused the flow speed to increase in order to comply with the required $\mathrm{W}_{\mathrm{c}}$ specified with the mass BC downstream. A local increase in flow velocity due to this blockage results in a lower static pressure than obtained for the flow without any blockage.

The airflow on the windward lip did not separate at $\alpha=25^{\circ}$. Nonetheless, this inlet operating condition serves as a test case to study the flow characteristics resulting from PARC3D calculations of the inlet with and without using the screen $\mathrm{BC}$ at the propeller face. Evaluation of the computational results indicated that the calculations predicted the ADP experimental inlet flow reasonably well. Also, the results show that the screen $\mathrm{BC}$ did simulated a flow blockage effect similar to the that associated with a wire-mesh screen. However, it has not yet been demonstrated how well this computational blockage could simulate the propeller effect as compared to the effect induced by the stationary blockage device used with the baseline inlet (Figs. $6 \& 7$ ). To further assess the effectiveness of the screen $B C$ subsequent calculations were carried out involving ADP inlet unstable flow (about to separate) and flow with separation.

\section{Angle of Attack of $29^{\circ}$ - Unstable Flow}

Figure 16 shows streamwise Mach contours on the inlet vertical center plane. The flow characteristics for $\alpha=29^{\circ}$ are similar in some aspects to those for $\alpha=25^{\circ}$ that was shown in figure 10 . The similarity includes locations of stagnation points on cowl windward and leeward sides, flow expansion and diffusion, and the blockage effect induced by the screen $\mathrm{BC}$ at the propeller face. The difference includes the local peak Mach number and the boundary layer thickness particular on the cowl windward side. Without the screen $\mathrm{BC}$, the local peak Mach number on the cowl windward highlight decreased from $M_{\mathrm{pk}}=1.27$ at $\alpha=25^{\circ}$ (Fig. 10(a)) to $\mathrm{M}_{\mathrm{pk}}=1.25$ at $\alpha=29^{\circ}$ (Fig. 16(a)). With the 
screen BC, the peak Mach number increased from $\mathrm{M}_{\mathrm{pk}}=1.29$ (Fig. 10(b)) to $\mathrm{M}_{\mathrm{pk}}=1.35$ (Fig. 16(b)). The reduction in the peak Mach number for the flow without the screen BC, based on reference 11, suggests that the flow at $\alpha=29^{\circ}$ may have separated. This separation is shown in the velocity vector distributions on the inlet cowl windward side in figure 17. Both calculations with and without the screen BC predicted that inlet-lip flow separation which occurred upstream near the highlight and continued downstream. With the screen BC, the flow reattached about $5 \mathrm{~cm}$ upstream of the propeller face. Without the screen BC, figure $17(\mathrm{~b})$ shows the flow separation extended past the propeller face and with the screen BC the flow downstream of the reattachment point stayed attached. This evidence reveals that the blockage effect induced by the screen BC was capable of suppressing the separation before it reached the propeller face.

Figure 18 shows circumferential static pressure contours for five cross sections at various locations upstream of the propeller face. In these plots, the effect of blockage induced by the screen BC is shown to propagate about $10 \mathrm{~cm}$ upstream of the propeller face. A comparison with similar static pressure contour plots for $\alpha=25^{\circ}$ in figure 11 indicates that the influence of the screen $\mathrm{BC}$ for a separated flow propagated further upstream than that for a non-separated flow. Figure 19 shows plots of circumferential static pressure over an inlet cross section $0.5 \mathrm{~cm}$ upstream of the propeller face station. Without the screen BC (Fig. 19(a)), a strong circumferential static pressure gradient is evident. With the screen BC (Fig. 19(b)), the static pressure contours are more uniform in the mainstream. In the flow region near the windward side, there are localized pockets of pressures that depict a complex flow field. This phenomenon could have evolved from the flow readjustment from separation to reattachment upstream.

Figure 20 shows a comparison of static pressure distributions from computational results with the ADP experimental data for $\mathrm{M}_{0}=0.2, \alpha=29^{\circ}$, and $\mathrm{W}_{\mathrm{c}}=21.12 \mathrm{~kg} / \mathrm{sec}$. On the windward side (Fig. 20(a)), the pressure distribution for the screen BC compares more favorably with the test data than the results obtained without the screen $\mathrm{BC}$, particularly around the inlet cowl highlight. On the leeward side (Fig. 20(B)), similar static pressure distributions from the two flow calculations are obtained. The distributions compare favorably with the test data on the inlet external surface but are slightly off on the internal surface. This comparison is similar to that for angle of attack of $25^{\circ}$, see figure 14(b). Figure 21 shows a comparison of circumferential static pressure distributions for a location $0.5 \mathrm{~cm}$ upstream of the propeller face. On the cowl side, the predicted distribution without the screen $B C$ is higher than that obtained with the screen $\mathrm{BC}$ and compares more favorably with the test data. On the center body the comparison shows a similar trend between the two predicted static pressure distributions. The difference is similar to the comparison for $\alpha=25^{\circ}$ that was shown in figure 15. The explanation, as discussed earlier for figure 15 , was due to the blockage effect of the screen BC causing the flow speed to increase in order to satisfy the required $\mathrm{W}_{c}$.

The ADP experimental data indicated that the inlet flow separated at $\alpha=30^{\circ}$ when the inlet was tested with the propeller. The inlet through-flow (without any blockage) was expected to separate a few degrees earlier. This was substantiated by the experimental evidence associated with the baseline inlet (Figs. $6 \&$ 7). The PARC3D calculation without the screen $\mathrm{BC}$ or through-flow simulation predicted inlet lip separation which persisted downstream past the propeller face. The level of the separation cannot be assessed due to the lack of the through-flow experimental data for the midlength inlet and details of the flow field for this inlet. The PARC3D calculation when using the screen BC also predicted inlet lip separation, but the flow reattached about $5 \mathrm{~cm}$ upstream of the propeller face where the screen $\mathrm{BC}$ was specified. The influence from the screen BC blockage effect appears to concur with the effect induced by the stationary blockage rods used with the baseline inlet (Figs. $6 \&$ 7). In order to assess the accuracy of the predicted flow field, details data are required.

\section{Angle of Attack of $30^{\circ}$ - With Separation}

Figure 22 shows Mach contours from the PARC3D calculation with the screen $\mathrm{BC}$ for $\mathrm{M}_{0}=0.2, \alpha=$ $30^{\circ}$, and $\mathrm{W}_{\mathrm{c}}=21.12 \mathrm{lbs} / \mathrm{sec}$. The flow on the cowl windward side stagnated on the outside surface just aft of the highlight. From this stagnation point the flow accelerated around the lip and reached a local peak Mach number of $\mathrm{M}_{\mathrm{pk}}=1.05$. A comparison of 
this peak Mach number with that for $\alpha=29^{\circ}$ (Fig. 16(b)) shows that it dropped from $\mathrm{M}_{\mathrm{pk}}=1.35$ to 1.05 as the angle of attack increased from $\alpha=29^{\circ}$ to $30^{\circ}$, respectively. Downstream of the highlight a thick flow boundary layer developed. The screen $\mathrm{BC}$ induced a blockage effect that tended to force the flow to become more uniform at the propeller face. It also induced a perturbation in the flow boundary layer resulting in a reduction in the boundary layer thickness a short distance downstream of the propeller face. On the cowl leeward side the flow stagnated near the highlight and the boundary layer which developed downstream on the internal surface is considerably thinner than on the cowl windward side. Figure 23(a) shows axial velocity vector distributions on the inlet cowl windward side. These velocity vectors shows that the flow separated just downstream of the highlight and continued with no appearance of reattachment. Figure 23(b) shows that the flow did reattach at a location $1.7 \mathrm{~cm}$ upstream of the propeller face. This reattachment point is $3.3 \mathrm{~cm}$ further downstream than for $\alpha=29^{\circ}$ as shown in figure $17(\mathrm{a})$.

Figure 24 shows a comparison of static pressure distributions between the ADP experimental results and the computational results with the screen BC. The experimental static pressure distribution indicates that the $\mathrm{ADP}$ inlet flow separated. Separation is indicated by the relatively flat pressure distribution around the highlight. The slight increase in pressure downstream of the highlight indicates that a small diffusion took place along the flow path. With the exception around the highlight region, a comparison on the cowl windward side shows that the predicted static pressure distribution agrees with the experimental data on the external and internal surfaces. However, just around the highlight the analysis predicted a peak static pressure value that is significantly lower than the experimental data. The reason for this is not readily understood at this point. The comparison on the inlet leeward side shows good agreement on the external surface and at the highlight but a small difference appears on the internal surface. Figure 25 shows a comparison of the circumferential static pressure distributions for a location $0.5 \mathrm{~cm}$ upstream of the propeller face. The distribution from the ADP experimental data is skewed to one side indicating that the ADP inlet flow separation may be unsteady. The comparison on the inlet cowl side shows that the predicted static distribution is lower than the experimental data.

\section{Future Study}

\section{Simulation of Propeller Effect}

The propeller in general is an active device which rotates thus generating a centrifugal force on the flow and adding energy to the flow. The effects induced by the propeller on oncoming flow include blockage, swirl, and suction. In this study the screen BC only induced a blockage effect on the flow field and a perturbation in the flow boundary layer. This blockage effect was passive and generates neither swirl nor suction on the oncoming flow. Instead of adding energy the screen BC created a momentum deficit in the flow field. Therefore, the blockage effect was the only commonality between the propeller and the screen BC. The suction in this ADP inlet study was generated using a mass BC downstream of the screen boundary. So the inlet flow calculation using the screen BC still neglected the swirl effect of the propeller. This could be a reason that the PARC3D calculations with and without the screen $\mathrm{BC}$ were unable to match the ADP experimental pressure distribution on the inlet cowl leeward side. A suggestion for future related work would be to include the swirl effect into the analysis in addition to the blockage effect; e.g., the screen BC. The most viable location for this swirl effect is at the propeller face. The amount of the swirl to be prescribed is left to a future study.

\section{Prediction of Flow Separation}

Predicting flow separation by CFD is still a challenge. The comparison in figure 24(a) shows the PARC3D calculation under predicted the inlet flow separation. Boundary layer separation has been known to evolve from a shock-boundary-layer interaction in a supersonic inlet flow, from an overexpanding supersonic flow through a nozzle, and from a strong adverse pressure gradient in a subsonic diffuser flow. With the ADP inlet at an angle of attack, the flow around the cowl windward highlight involved a rapid expansion from a stagnation point followed by a diffusion with a local supersonic flow in between. All of these flow phenomena occurred over a very short distance. 
The physics of this type of flow are complex and the separation associated with this phenomenon is even more complicated. The PARC3D code uses the Baldwin-Lomax turbulence model which according to an analysis done by G.J. Harloff et al. [18] predicted a late separation of flow through an Sduct. To further evaluate the type of flow separation associated with the ADP inlet at take-off, a future numerical study is suggested in which a different type of turbulence model such as the nonequilibrium turbulence closure model (NTM) by D.A. Johnson and L.S. King [19] and/or the Chen and Patel two layer $\kappa-\epsilon$ model [20]. The NTM turbulence model requires slightly more computational efforts than the Baldwin-Lomax algebraic model. The NTM model was developed specifically for 2-D flow turbulent boundary layer calculations, so it may require a substantial amount of work to modify for 3-D flows.

\section{Conclusion}

A numerical study was implemented to evaluate the aerodynamic performance of an ADP subsonic inlet at take-off operating conditions with a free stream Mach number of 0.2 and angles of attack $25^{\circ}, 29^{\circ}$, and $30^{\circ}$. An existing 3-D RANS flow solver called the PARC3D code was utilized in the study. A computational mass $\mathrm{BC}$ was specified at the inlet nacelle exit to induce a required mass flow rate of $21.12 \mathrm{~kg} / \mathrm{sec}$ through the inlet. At the propeller face a computational screen $\mathrm{BC}$ was specified in an attempt to simulate a blockage effect induced by the propeller. When the screen $\mathrm{BC}$ was removed, the flow calculation simply represented a through-flow inlet (no propeller). The computational results were assessed through comparisons with the inletwith-propeller (ADP) inlet experimental data. The following findings have been concluded from this numerical study:

1. The screen BC which was specified at the propeller face induced a flow blockage effect on the inlet flow field. This blockage effect forced the flow to become more uniform at the propeller face relative to the flow field obtained without the screen BC. In addition it also induced a perturbation in the boundary layer as the flow passed through the screen.

2. At $\alpha=25^{\circ}$ the numerical results obtained indicate that the inlet flow was attached as indicated by the ADP experimental test data. The blockage effect induced by the screen $\mathrm{BC}$ propagated a very short distance about $3 \mathrm{~cm}$ upstream of the propeller face. These results suggest that, for attached flow the effect of the blockage downstream may not be of any significance for the inlet flow upstream.

3. At $\alpha=29^{\circ}$, the PARC3D calculations predicted flow separation on the inlet lip. The blockage effect induced by the screen BC propagated about onehalf the distance between the propeller face and the inlet hightlight, about $10 \mathrm{~cm}$ upstream of propeller face. With the screen BC, the separated flow was forced to reattach at $5.0 \mathrm{~cm}$ upstream of the screen. Without the screen BC, the separation persisted downstream beyond the propeller face location. This evidence shows that the blockage effect induced by the screen BC was capable of suppressing the flow separation after it had occurred, thus improving the inlet flow performance. These characteristics of the screen $\mathrm{BC}$ are supported by experimental data for the baseline inlet when tested with the blockage rods.

4. At $\alpha=30^{\circ}$, the numerical results predicted flow separation on the inlet lip consistent with the ADP experimental test data. Due to the blockage effect induced by the screen BC, the separated flow reattached at $1.7 \mathrm{~cm}$ upstream of the propeller face.

\section{$\underline{\text { References }}$}

1. Wie, Y.S.,"Design of a Hybrid Laminar Flow Control Engine Nacelle," ALAA paper 90-0400, Jan. 1992.

2. Valarezo, W.O.,"Calculation of Subsonic Shrouded Propeller Flows," AIAA paper 90-0029, Jan. 1990.

3. Mendenhall, M.R. and Spangler, S.B.,"Theoretical Study of Ducted Fan Performance," NASA CR1494, 1970.

4. Mendenhall, M.R. and Spangler, S.B.,"A Computer Program for the Prediction of Ducted Fan Performance," NASA CR-1495, 1970.

5. Chen, H.C., Yu, N.J., and Rubbert, P.E.,"Flow Simulation for General Nacelle Configurations 
Using Euler Equations," AIAA paper Jan. 1983.

6. Uenishi, K., et al.,"CFD-Based 3D Turbofan Nacelle Design System," AIAA paper, August 1990.

7. Hirose, N. and Asai, K.,"Euler Flow Analysis of Turbine Powered Simulation and Fanjet Engine," Journal of Jet Propulsion, Vol. 7, No. 6, Nov.- Dec. 1991.

8. Nakahashi, K.,"FDM - FEM Zonal Approach for Viscous Flow Computations Over Multiple-Bodies," AIAA paper 87-0604, Jan. 1992.

9. Srivastava, R.,"An Unsteady Euler Scheme for the Analysis of Ducted Propellers," AIAA paper 920522, Jan. 1992.

10. Hall, E.J. and Delany, R.A.,"3D Euler Analysis of Ducted Propfan Flowfields," AIAA paper 903034, Aug. 1990.

11. Boldman, D.R., Iek, C., Jeracki, R.J., Larkin M., and Sorin G.,"Evaluation of Panel Code Predictions with Experimental Results of Inlet Performance for a 17-inch Ducted Prop/Fan Simulator Operating at Mach 0.2," AIAA paper 91-3354, Jun. 1991.

12. Larkin, M.J. and Schweiger, P.S.,"Ultra High Bypass Nacelle Aerodynamics: Inlet Flow-Through High Angle of Attack Distortion Test," NASA CR189149, Jul. 1992.

13. Cooper, G.K. and Sirbuagh, J.R.,"The PARC Distinction: A Practical Flow Simulator," AIAA paper 90-2002, Jul. 1990.
14. Steinbrenner, J.P. and Chawner, J.R.,"Enhancements to the Gridgen System for Increased User Efficiency and Grid Quality," AIAA paper 92-0662, Jan. 1992.

15. Iek, C., Boldman, R.D., and Ibrahim, M.,"Analysis of an Advanced Ducted Propeller Subsonic Inlet," AIAA paper 92-0274, Jan. 1992.

16. Horlock, J.H.," Actuator Disk Theory," McGrawHill Inc., New York, New York, 1978.

17. Pinker, R.A. and Herbert, M.V.,"Pressure Loss Associated with Compressible Flow Through Square-Mesh Wire Gauges," Journal Mechanical Engineering Science, Vol. 9, No. 1, 1967, pp. 11-23.

18. Harloff, G.J., Reichert, B.A., and Wellborn, S.R.,"Navier-Stokes Analysis and Experimental Data Comparison of Compressible Flow in a Diffusing SDuct," AIAA paper 92-6299, Jun. 1992.

19. Johnson, D.A. and King, L.S.,"A Mathematical Simple Turbulence Closure Model for Attached and Separated Turbulent Boundary Layers," ALAA Journal, Vol. 23, No. 11, Nov. 1985.

20. Chen H.C. and Patel V.C.,"Near-Wall Turbulent Models for Complex Flows Including Separation," AIAA Journal, Vol. 26, No. 6, Jun. 1988. 
Page intentionally left blank 


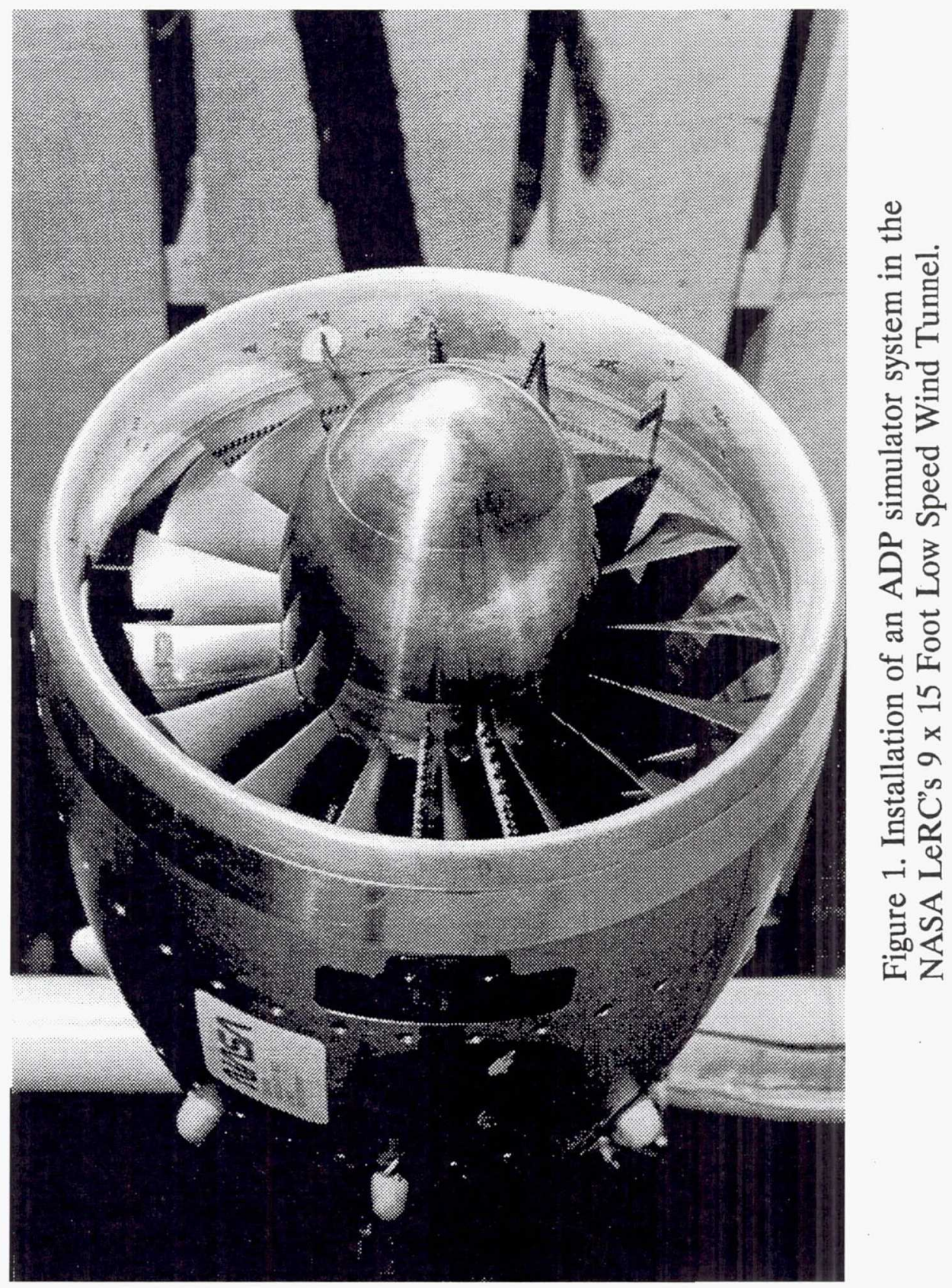


Page intentionally left blank 


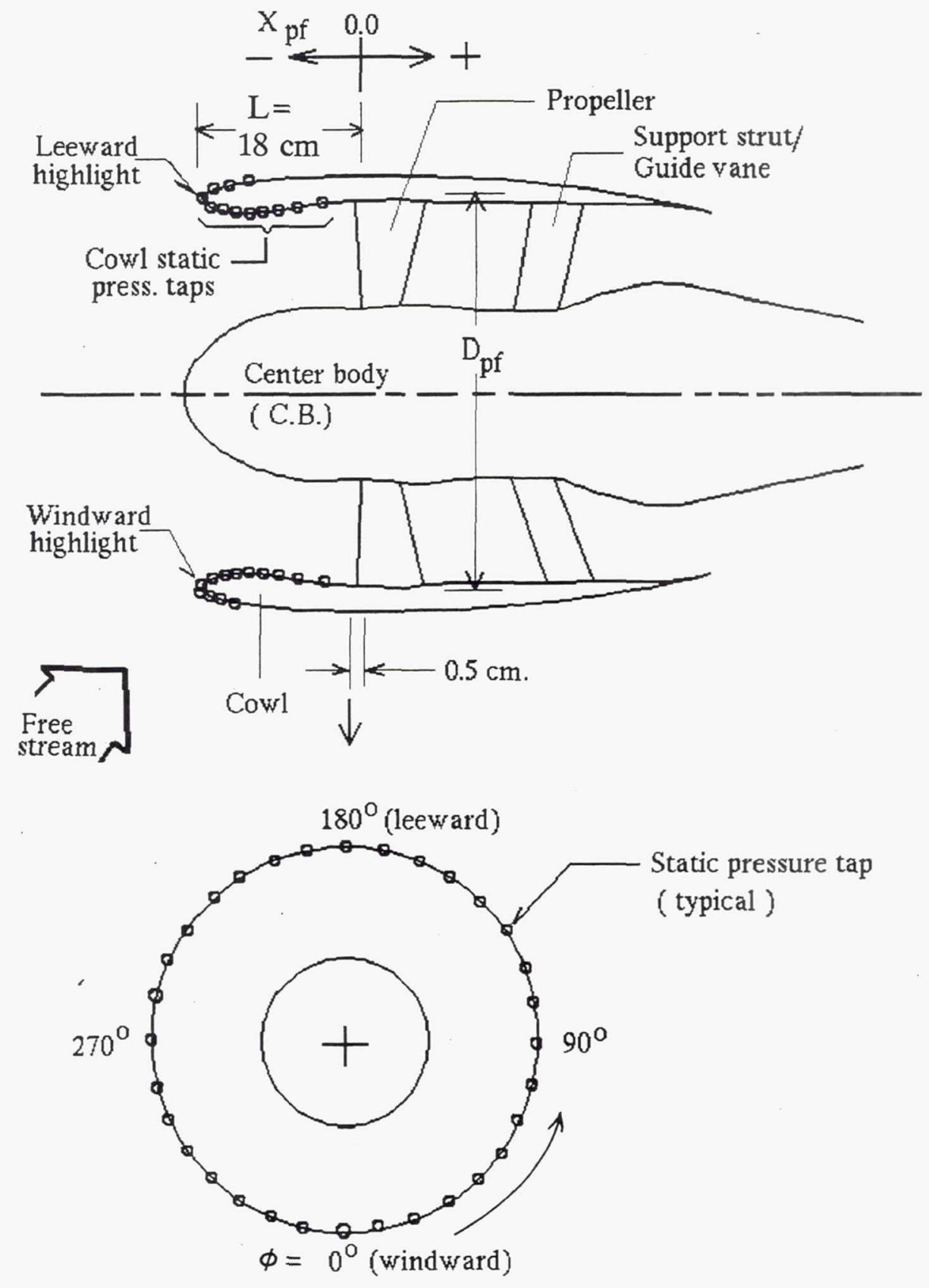

Figure 2. Schematic of the ADP simulator with the static pressure instrumentation. 
Page intentionally left blank 


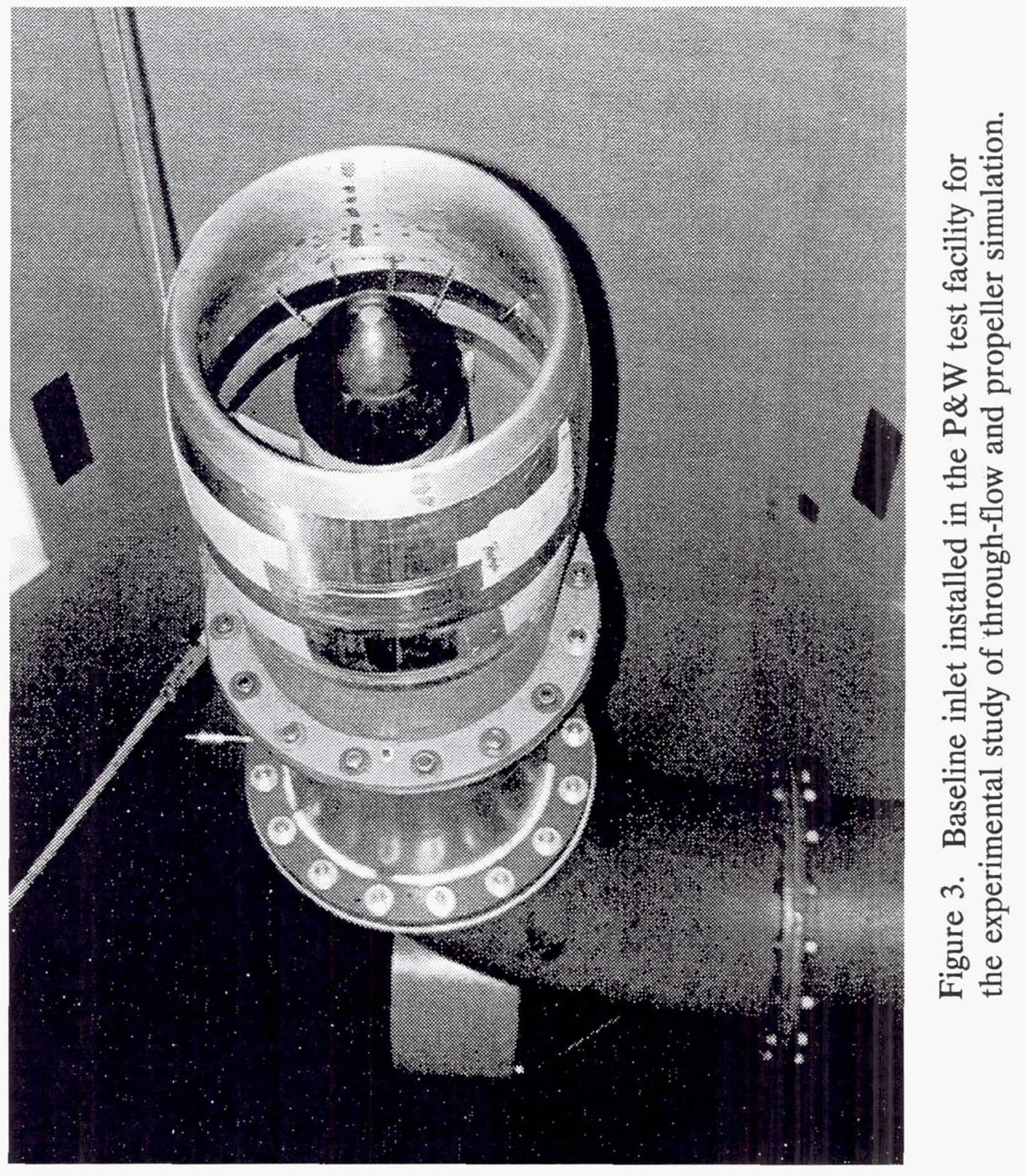


Page intentionally left blank 


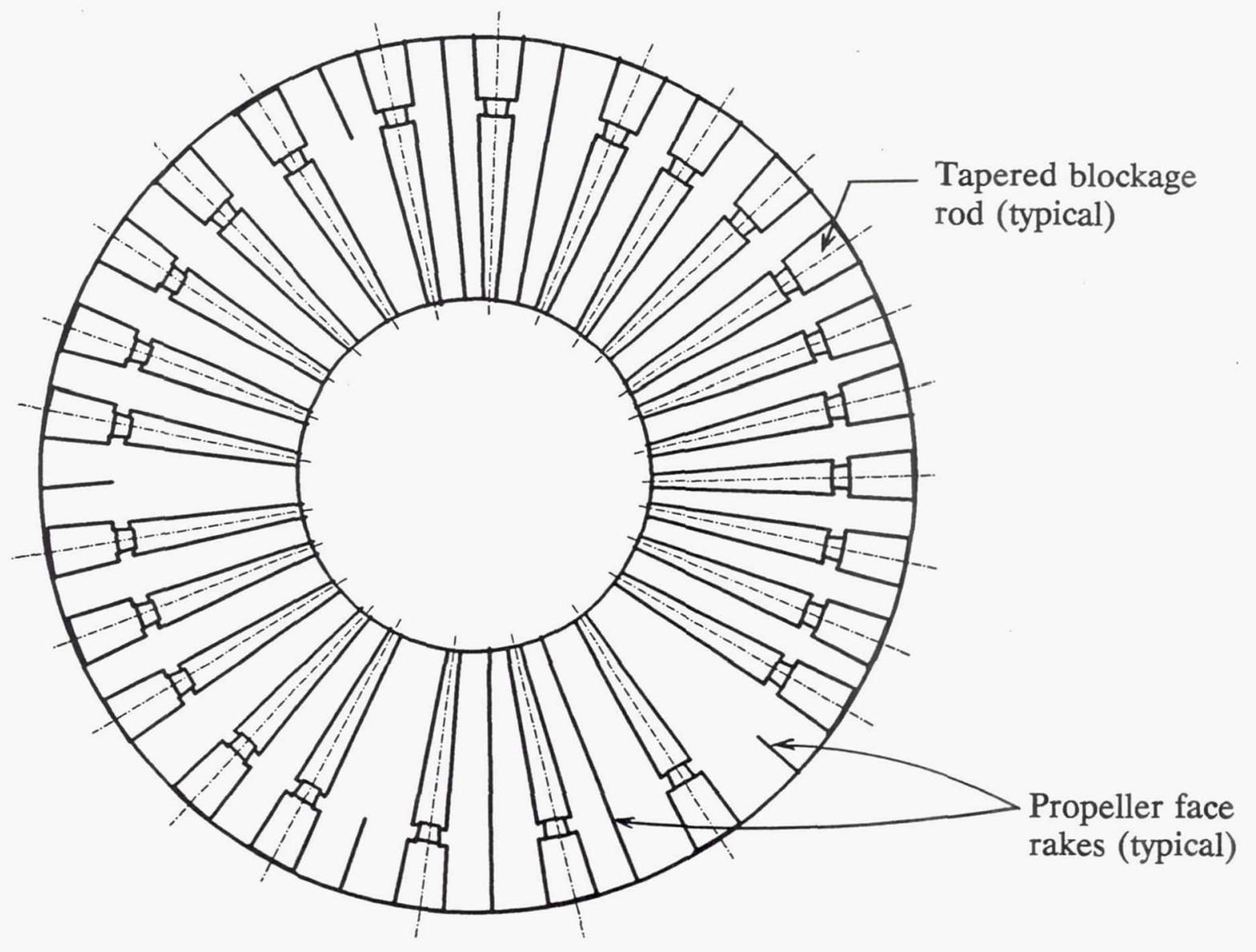

Figure 4. Blockage rods used at the propeller face of the baseline inlet. 


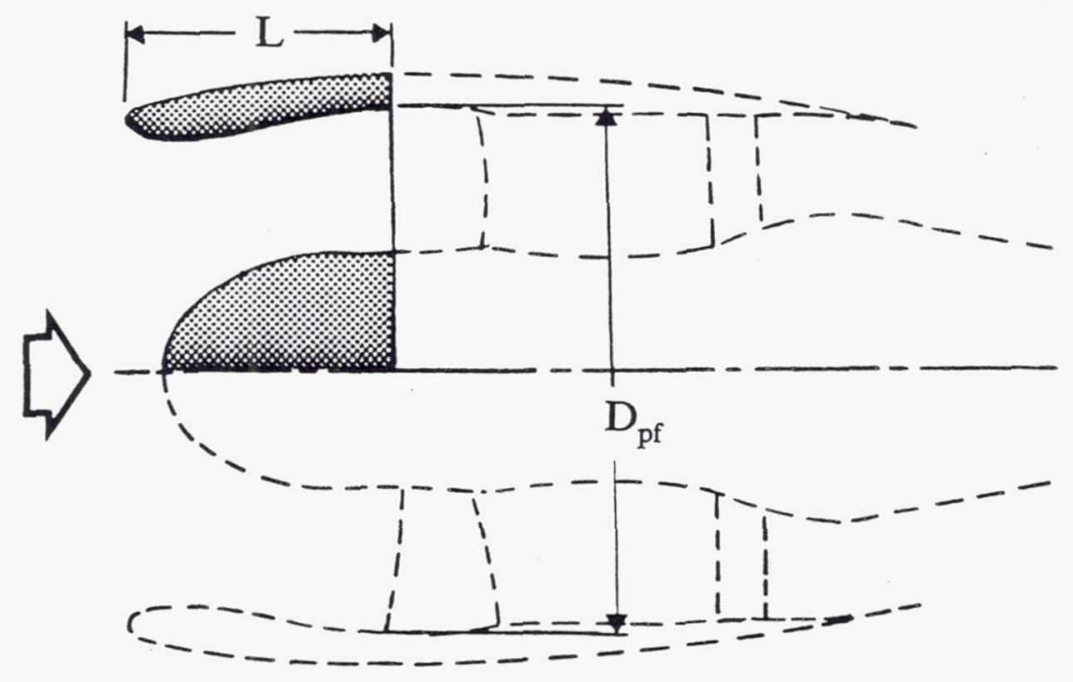

(a) Baseline; $\mathrm{L} / \mathrm{D}_{\mathrm{pf}}=0.5$

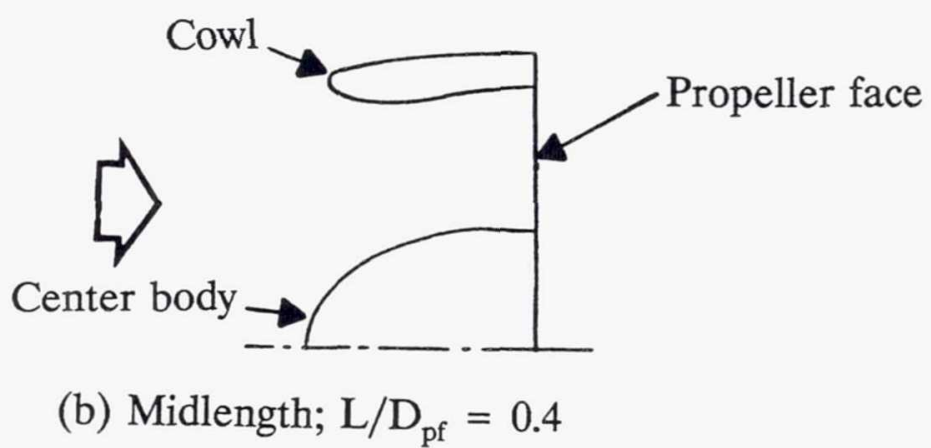

Note: (a) was tested with through-flow and prop. effect simulation and (b) was used in this numerical study.

Figure 5. Comparison of two ADP inlet configurations. 


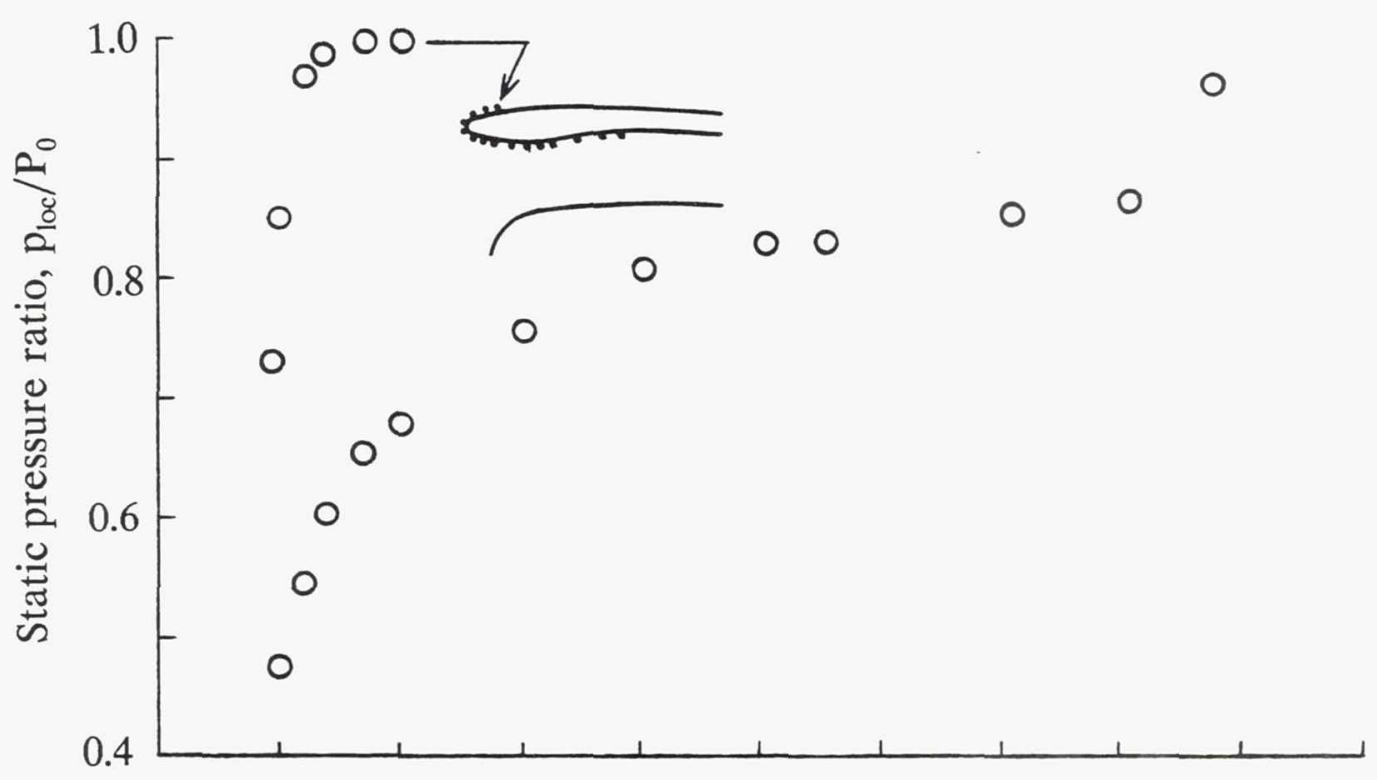

(a) Before separation, $\alpha=25^{\circ}$.

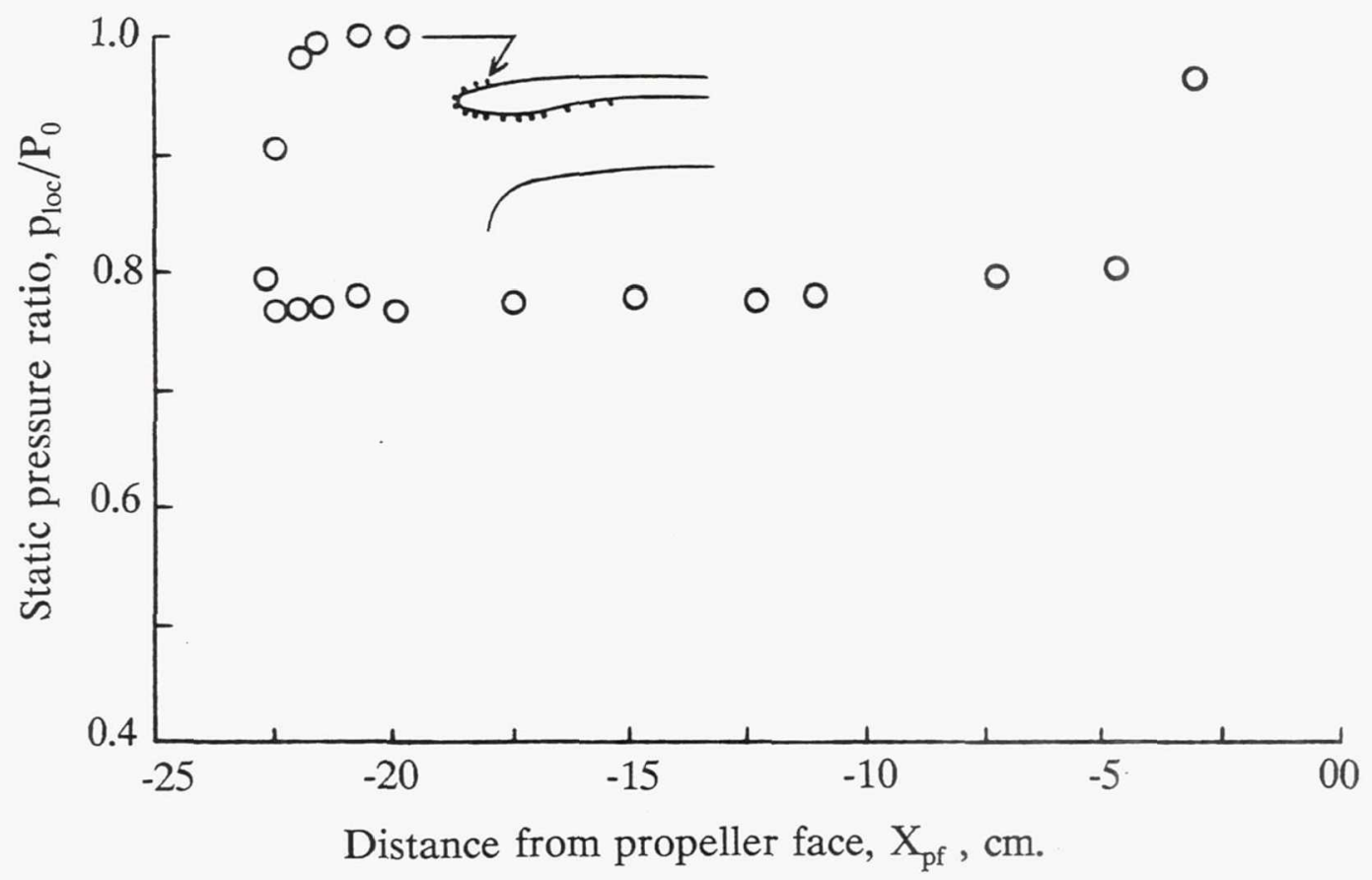

(b) After separation, $\alpha=26^{\circ}$.

Figure 6. Baseline inlet experimental static pressure distributions on the cowl windward for through-flow at $\mathrm{M}_{0}=0.2$ and $\mathrm{W}_{\mathrm{c}}=17.41 \mathrm{~kg} / \mathrm{sec}$. 

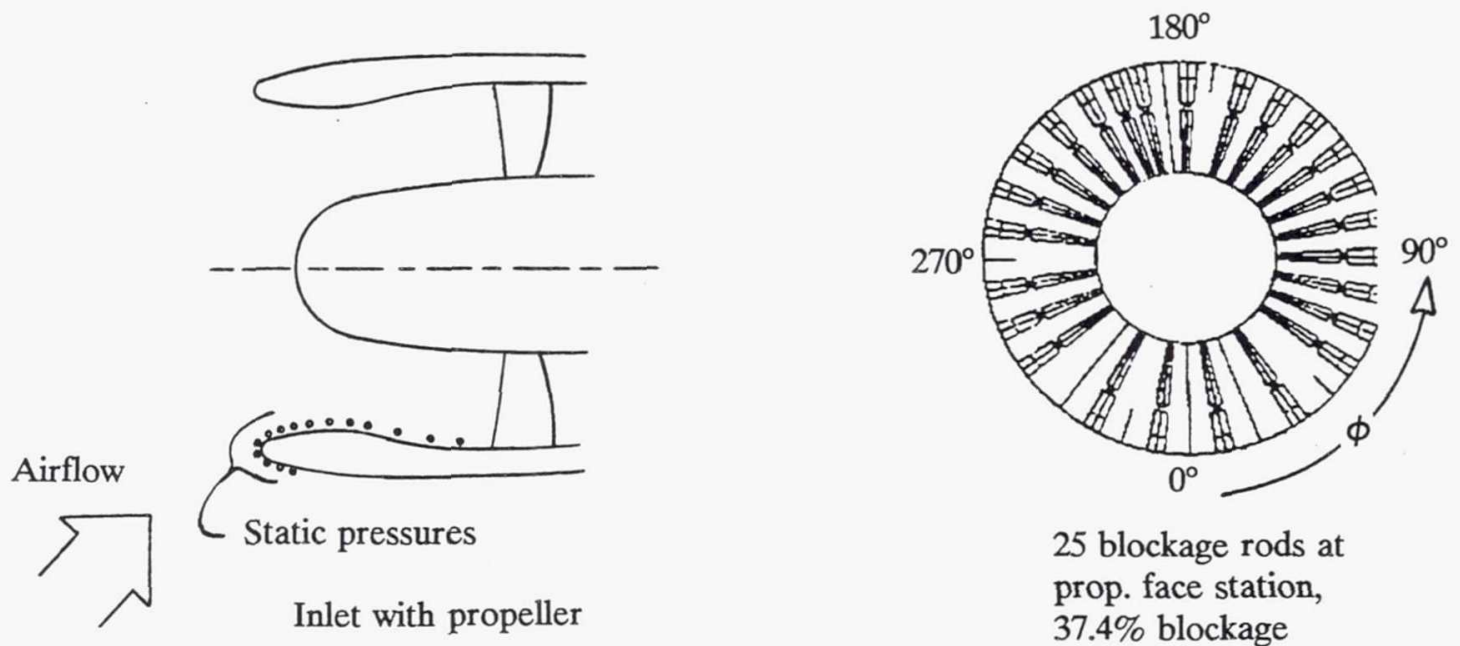

25 blockage rods at prop. face station, $37.4 \%$ blockage
Inlet with
o propeller
$\triangle$ blockage rods
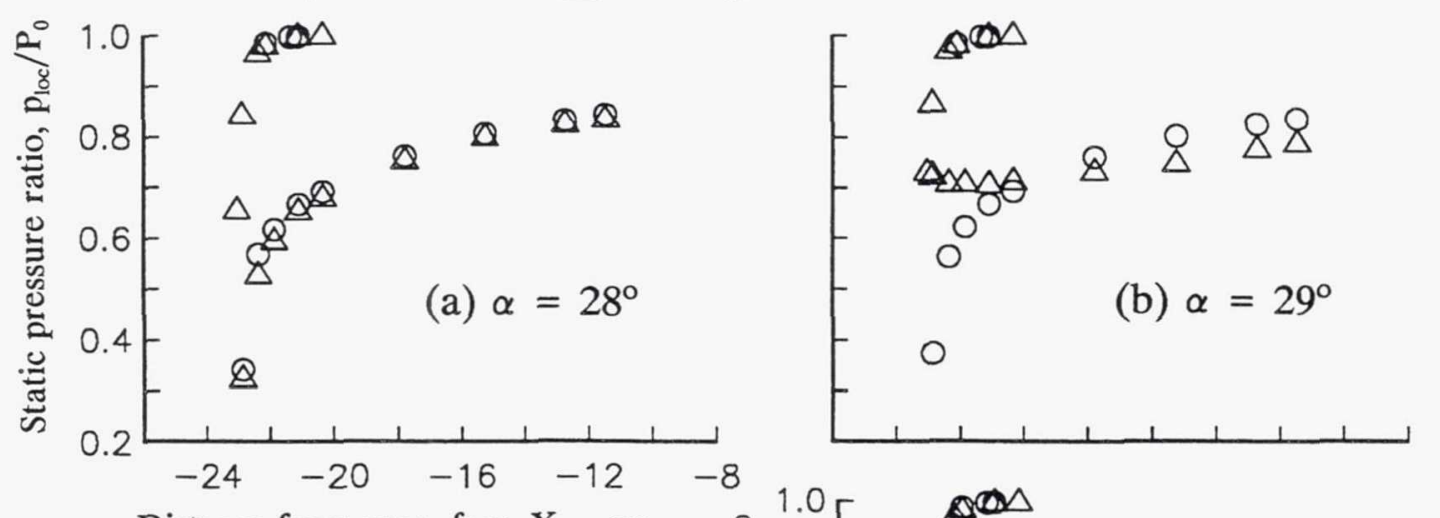

Distance from prop. face, $\mathrm{X}_{\mathrm{pt}}, \mathrm{cm}$.

Figure 7. Comparison of baseline inlet windward static pressure distributions from experiments for $\mathrm{M}_{0}=0.2$ and $\mathrm{W}_{\mathrm{c}}=17.41 \mathrm{~kg} / \mathrm{sec}$.

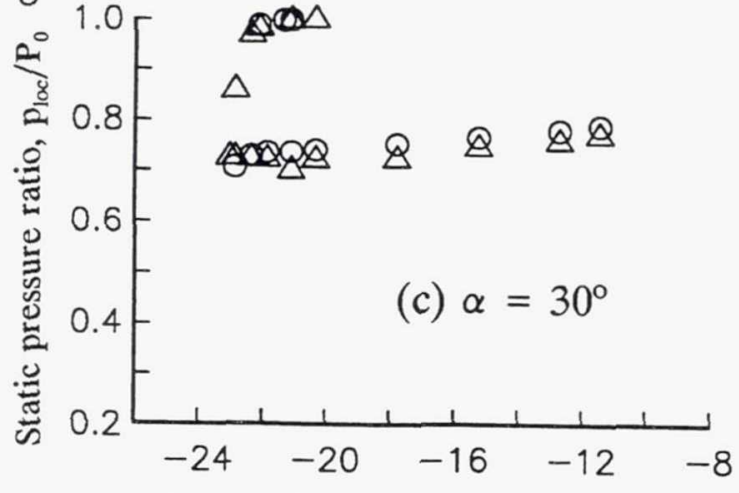

Distance from prop. face, $\mathrm{X}_{\mathrm{pt}}, \mathrm{cm}$. 


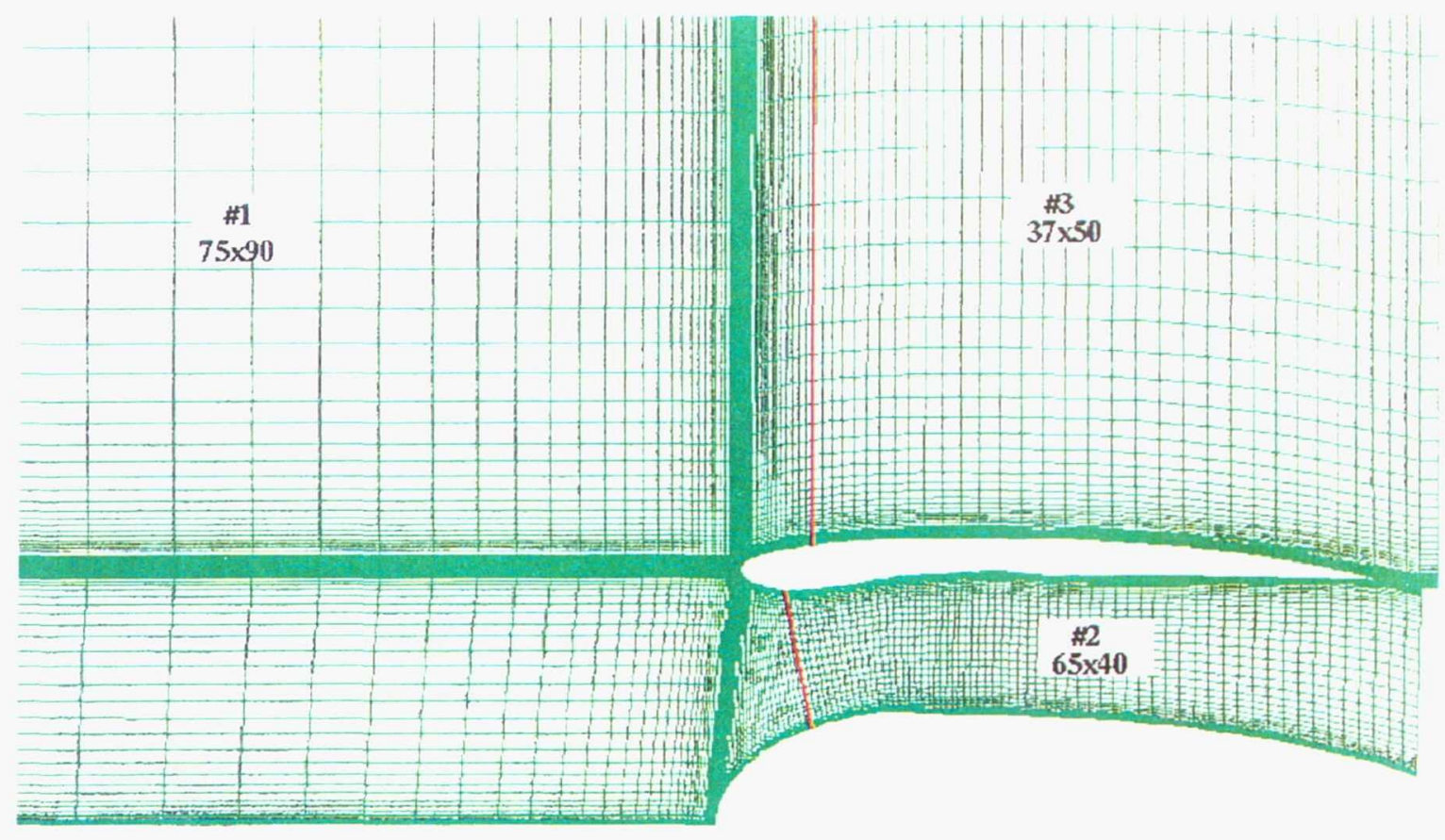

2-D H-grid
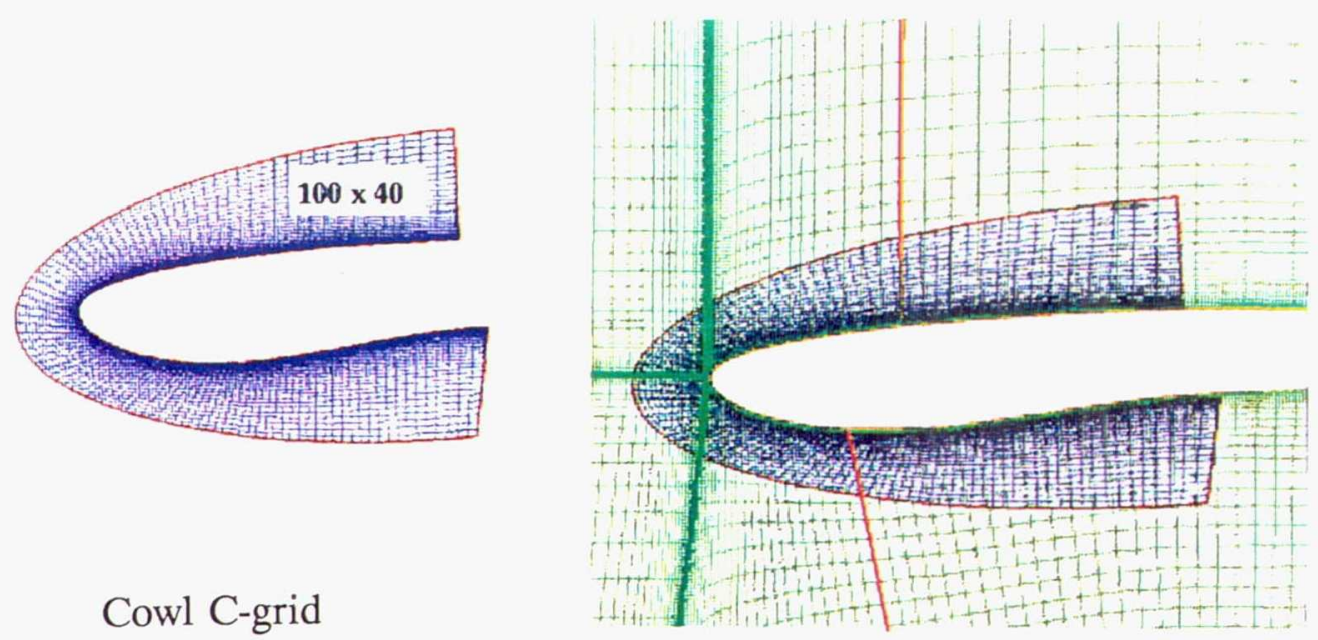

$\mathrm{H}$-grid with embedded C-grid

(a) 2-D grid.

Figure 8. Computational grids. 
Page intentionally left blank 

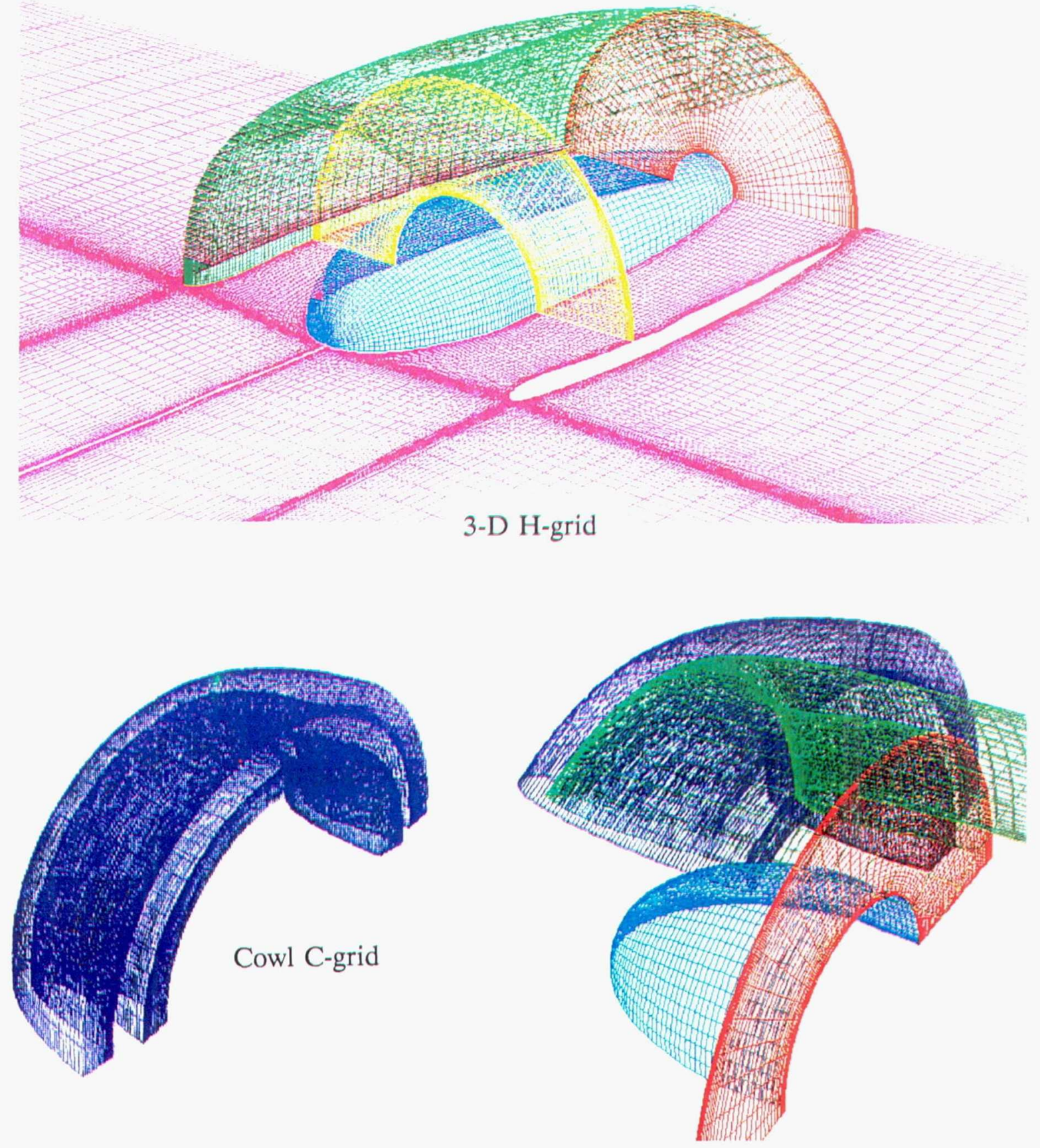

$\mathrm{H}$-grid with embedded C-grid

(b) 3-D grid.

Figure 8. Concluded. 
Page intentionally left blank 


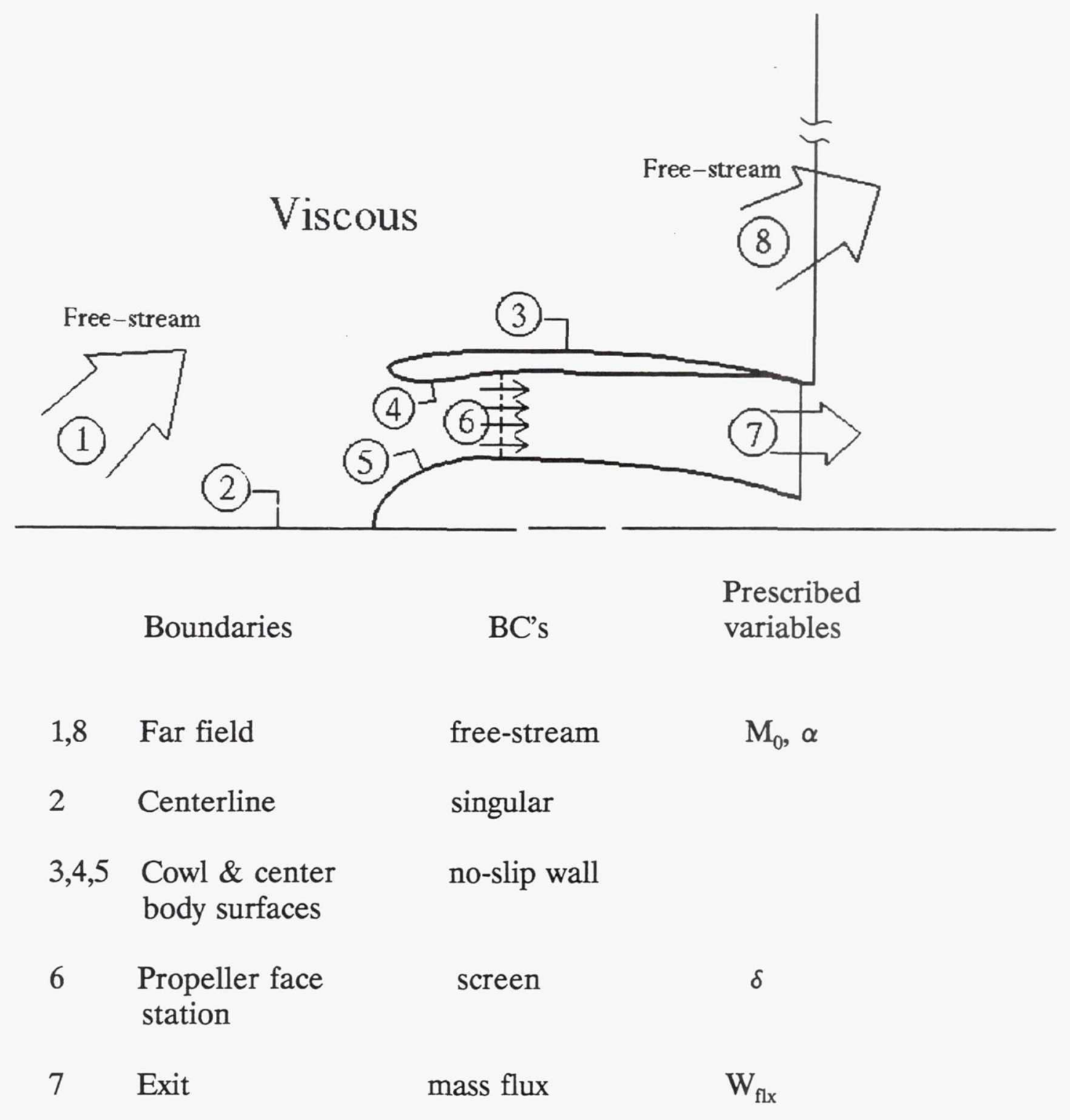

Figure 9. PARC BC's applied in analyses using screen $\mathrm{BC}$ 's at the propeller face. 
Page intentionally left blank 


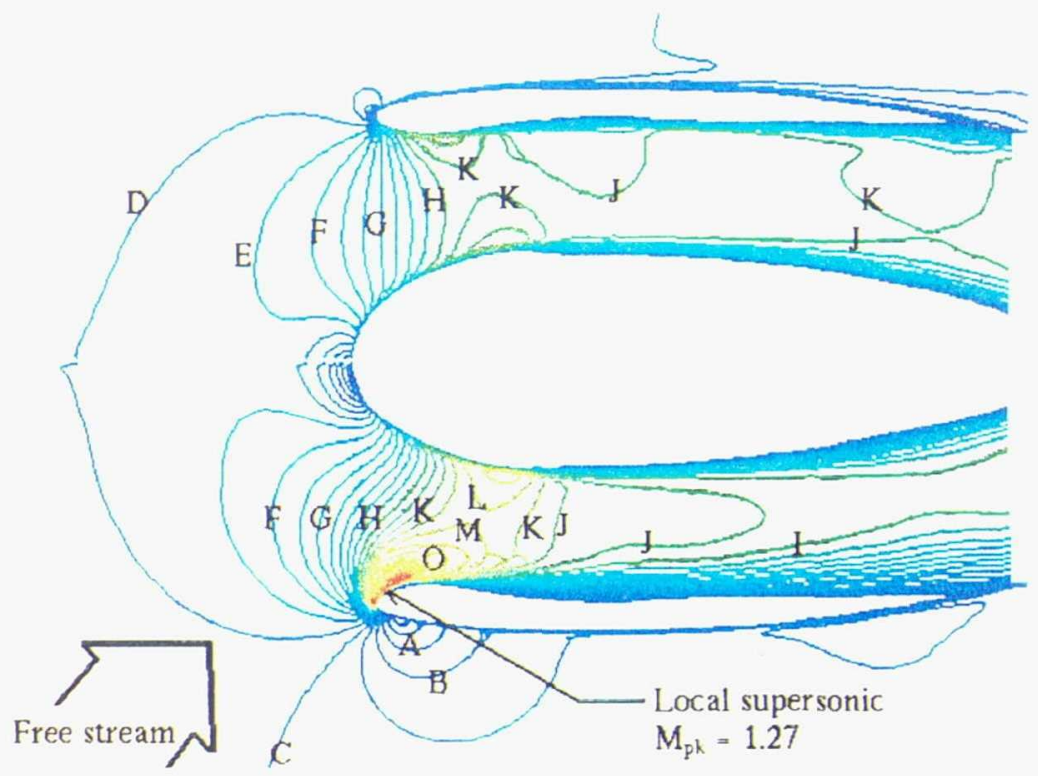

(a) With no screen BC.

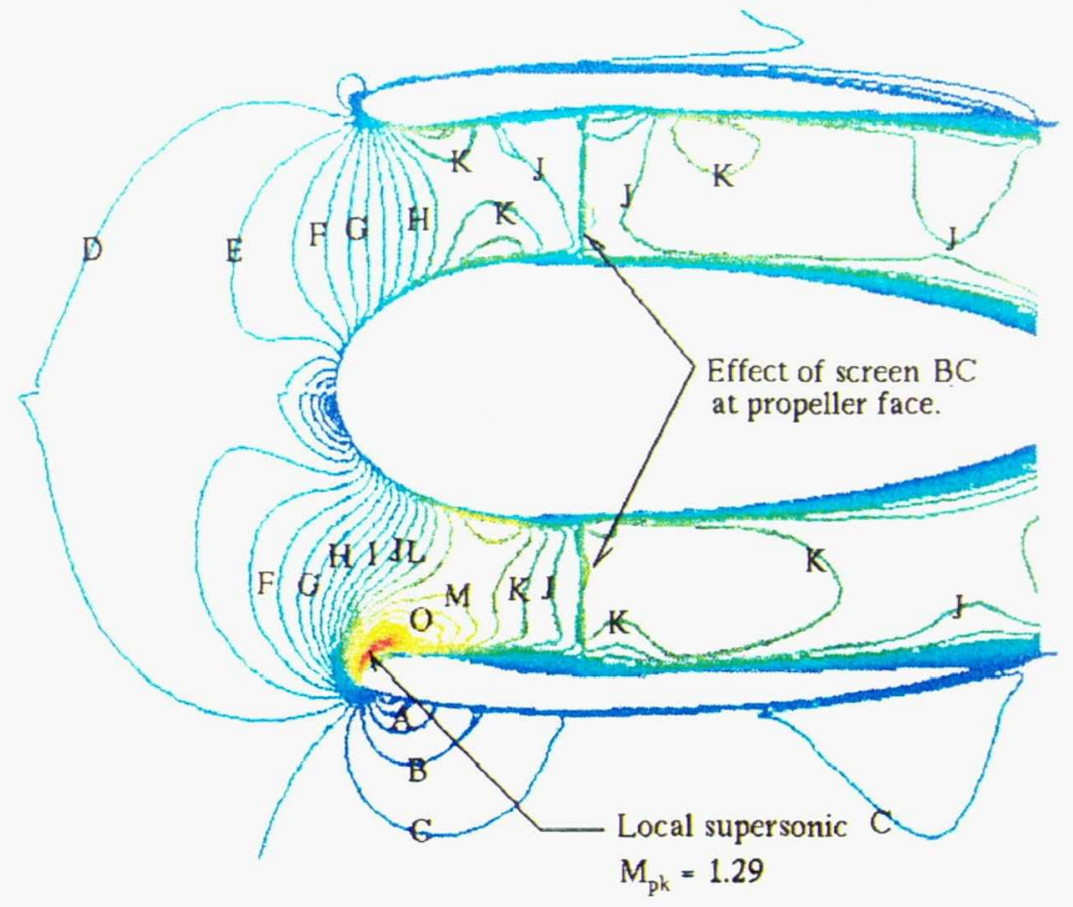

(b) With screen BC.
Local Mach
number

A 0.07

B 0.12

C 0.19

D 0.22

E 0.24

F 0.29

G 0.36

H 0.43

I 0.48

J 0.53

K 0.56

L 0.58

M 0.62

N 0.67

O 0.70

Figure 10. Mach contours over the inlet center plane for $\mathrm{M}_{0}=0.2, \alpha=25^{\circ}$, and $\mathrm{W}_{\mathrm{c}}=21.12 \mathrm{~kg} / \mathrm{sec}$. 
Page intentionally left blank 


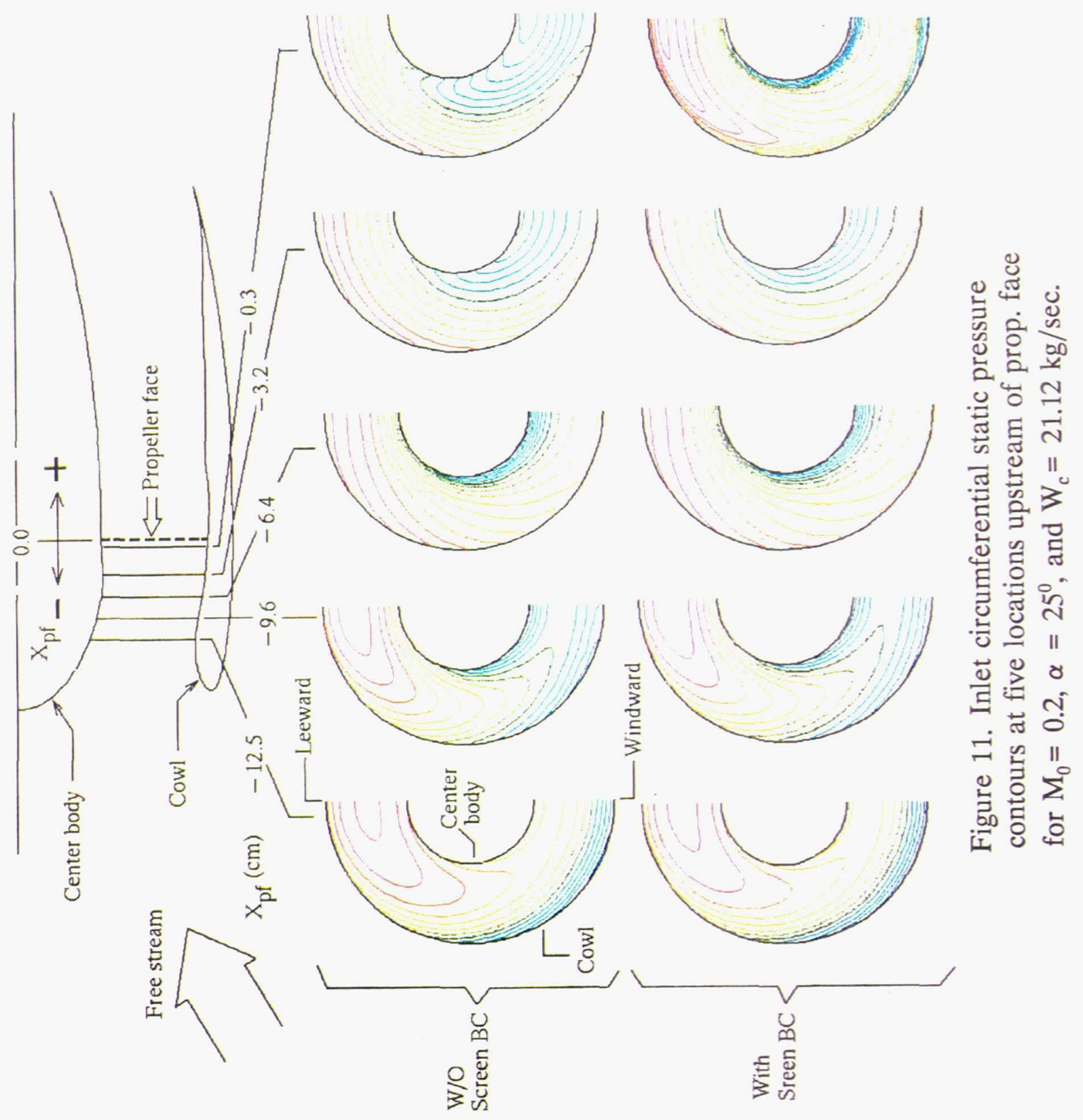


Page intentionally left blank 

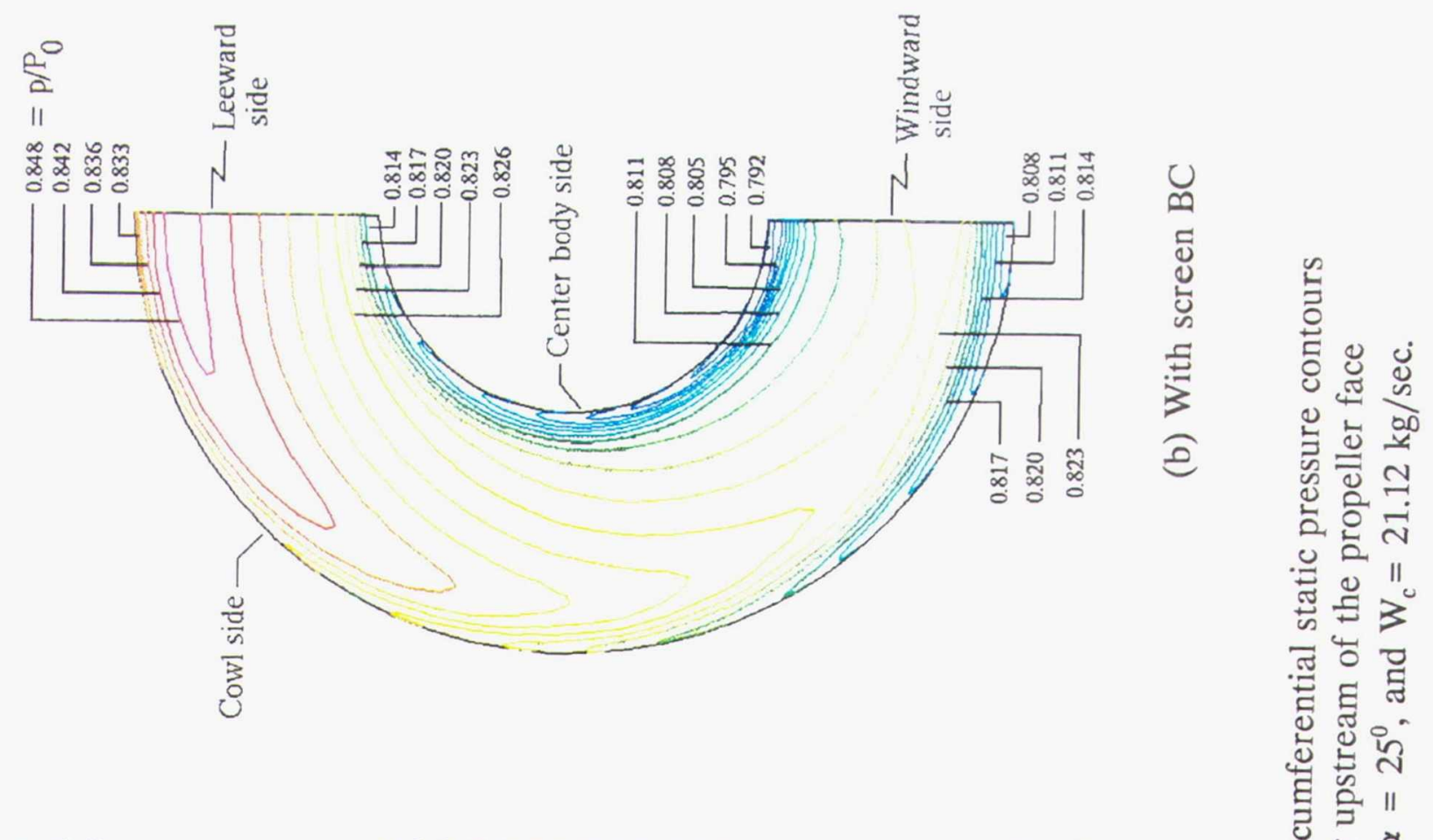

善 善

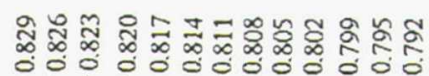

홍 ⿳⼈ㅁㅇ

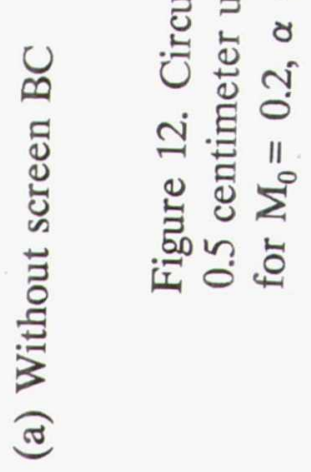

स्

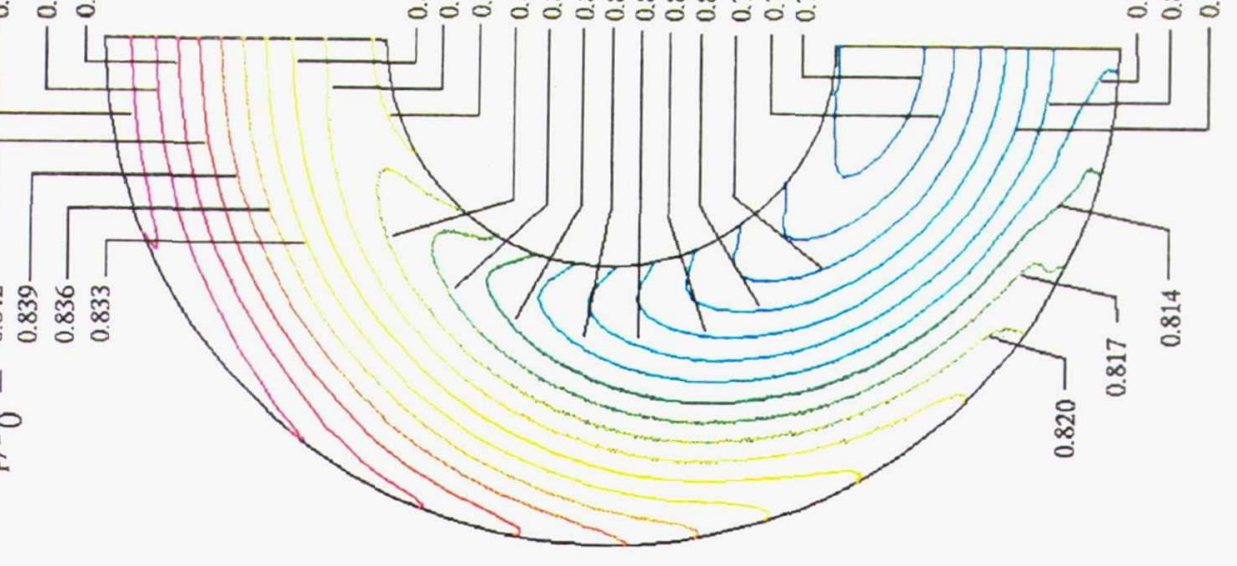


Page intentionally left blank 


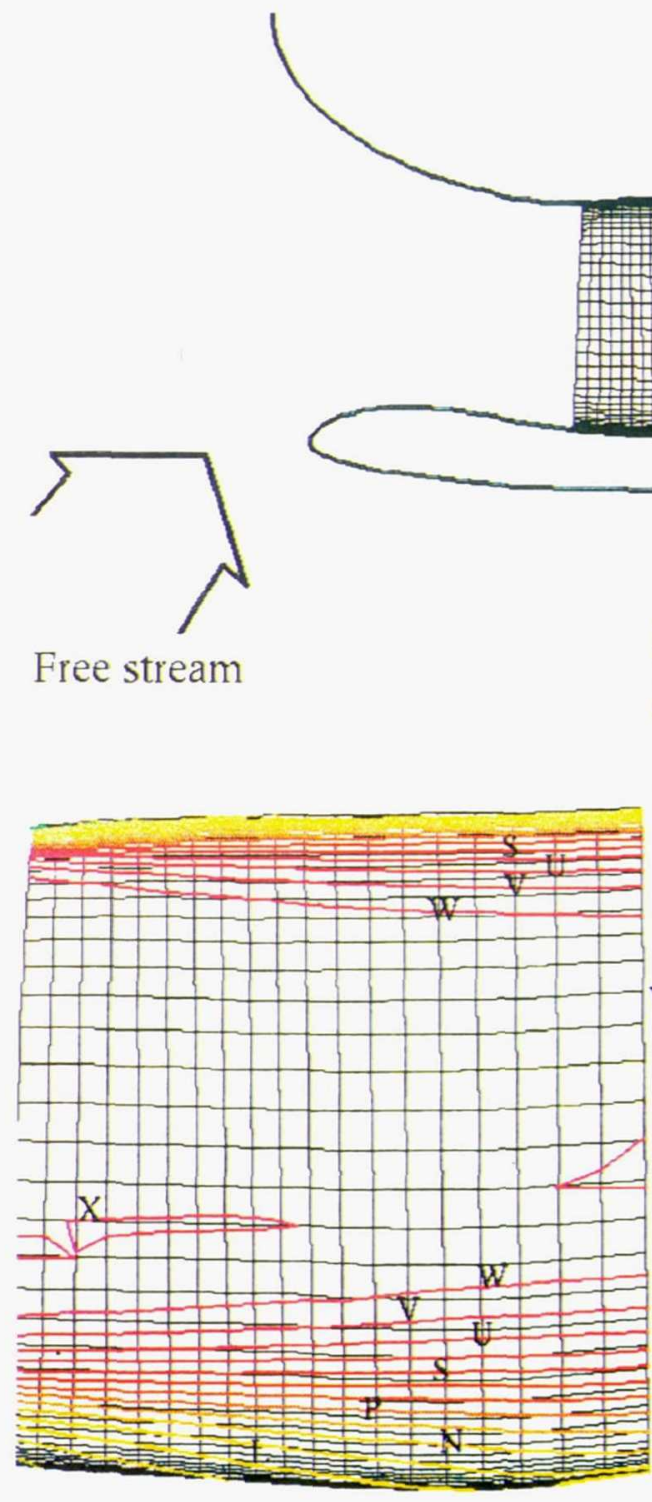

(a) Without screen BC.

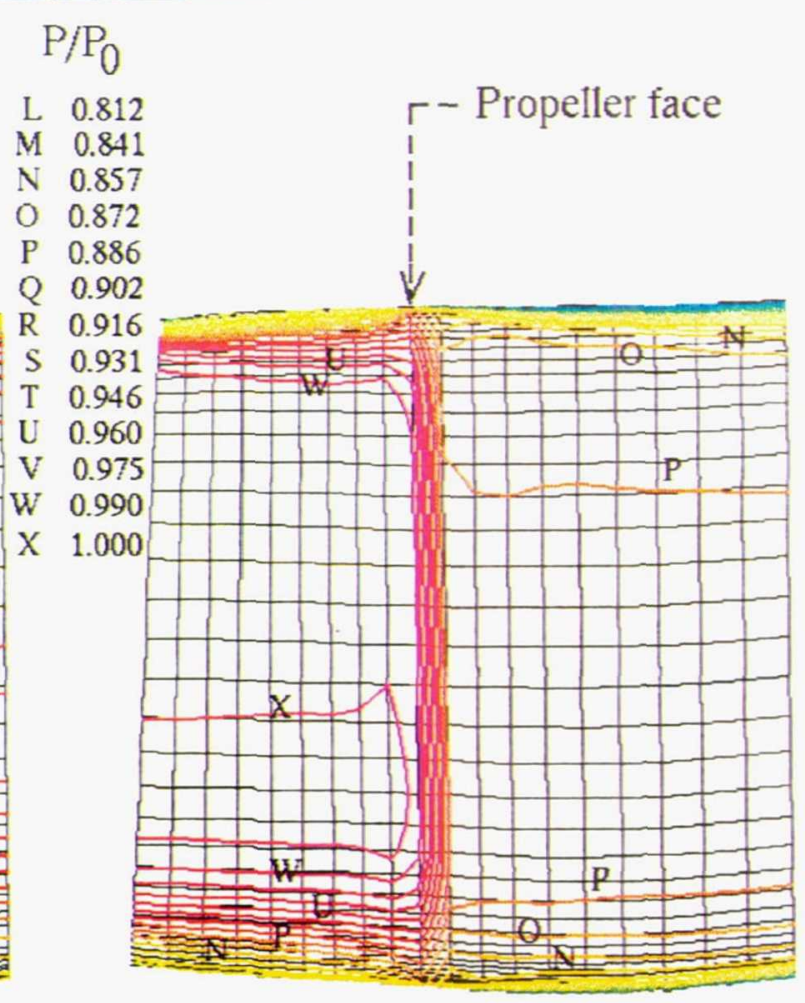

(b) With screen BC.

Figure 13. Axial total pressure contours on the inlet windward side in region surrounding the propeller face for $\mathrm{M}_{0}=0.2, \alpha=25^{\circ}$, and $\mathrm{W}_{\mathrm{c}}=21.12 \mathrm{~kg} / \mathrm{sec}$. 
Page intentionally left blank 


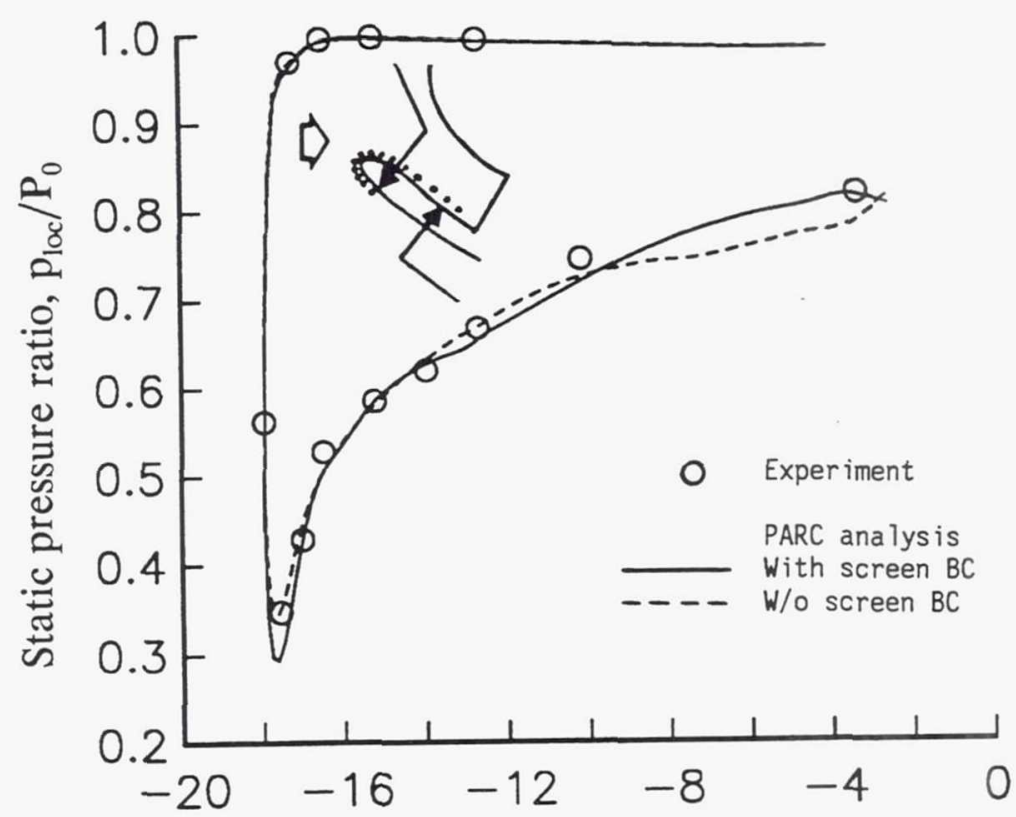

(a) Windward side, $\phi=0^{\circ}$

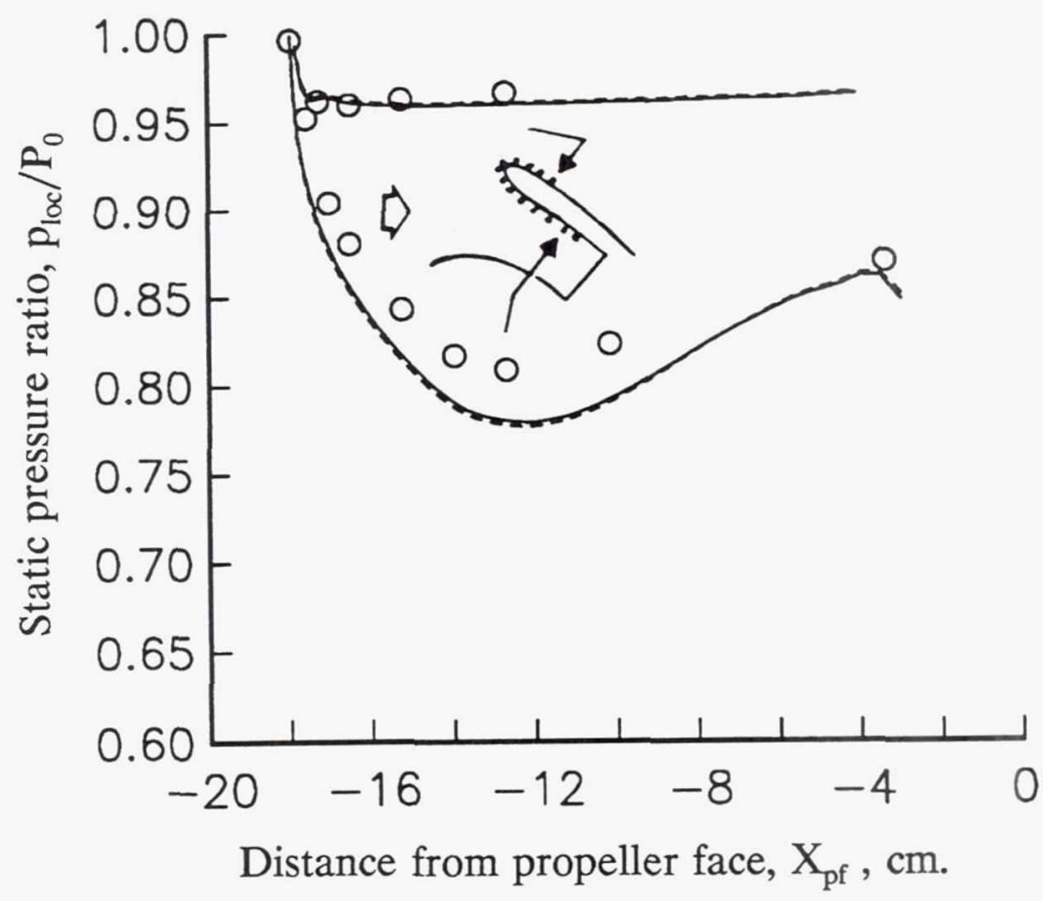

(b) Leeward side, $\phi=180^{\circ}$

Figure 14. Comparison of static pressure distributions between analyses and ADP experiment for $\mathrm{M}_{0}=0.2$, $\alpha=25^{\circ}$, and $\mathrm{W}_{\mathrm{c}}=21.12 \mathrm{~kg} / \mathrm{sec}$. 


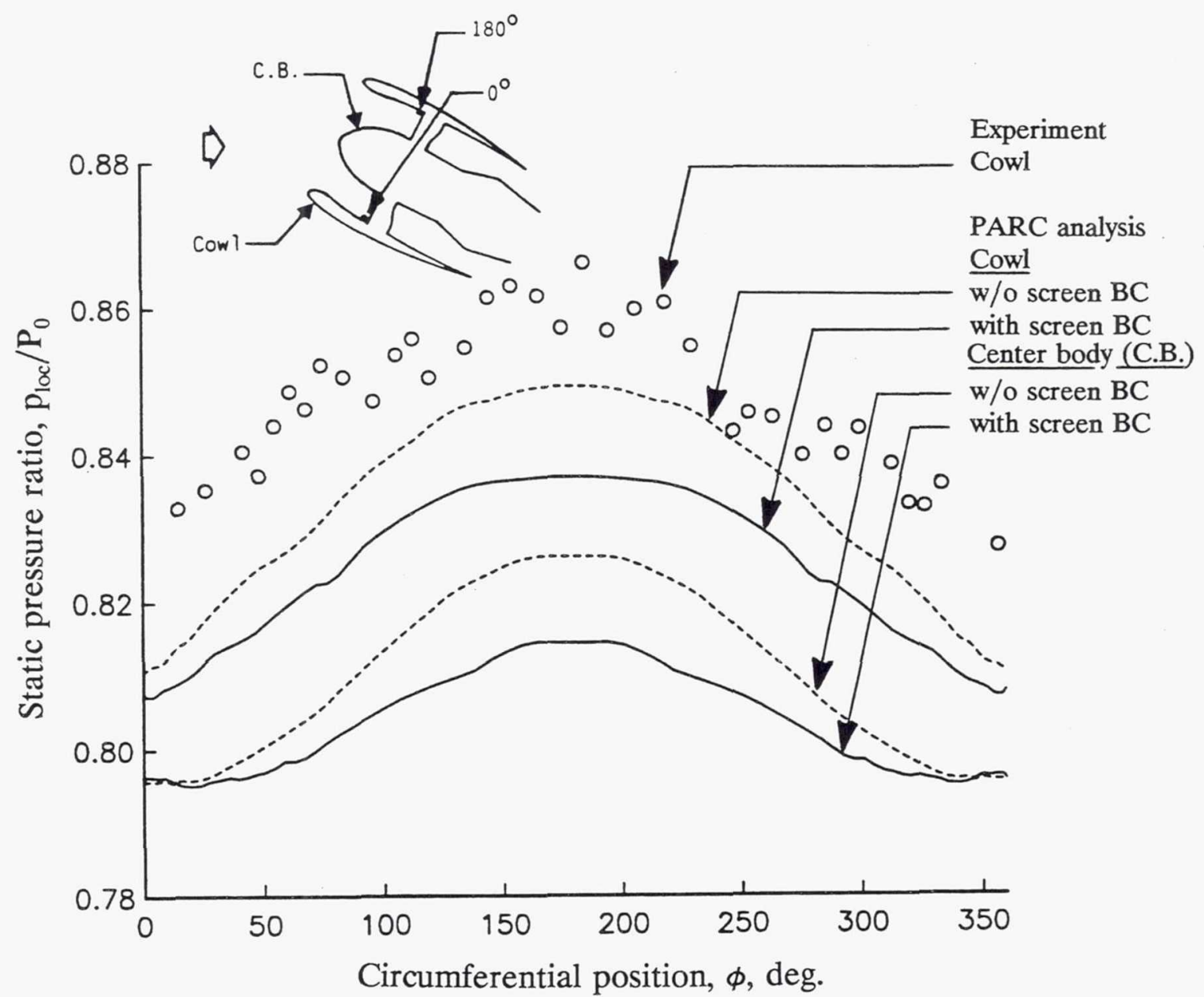

Figure 15. Comparison of circumferential static pressure distributions $0.5 \mathrm{~cm}$ upstream of the propeller face for $\mathrm{M}_{0}=0.2, \alpha=25^{\circ}$, and $\mathrm{W}_{\mathrm{c}}=21.12 \mathrm{~kg} / \mathrm{sec}$. 


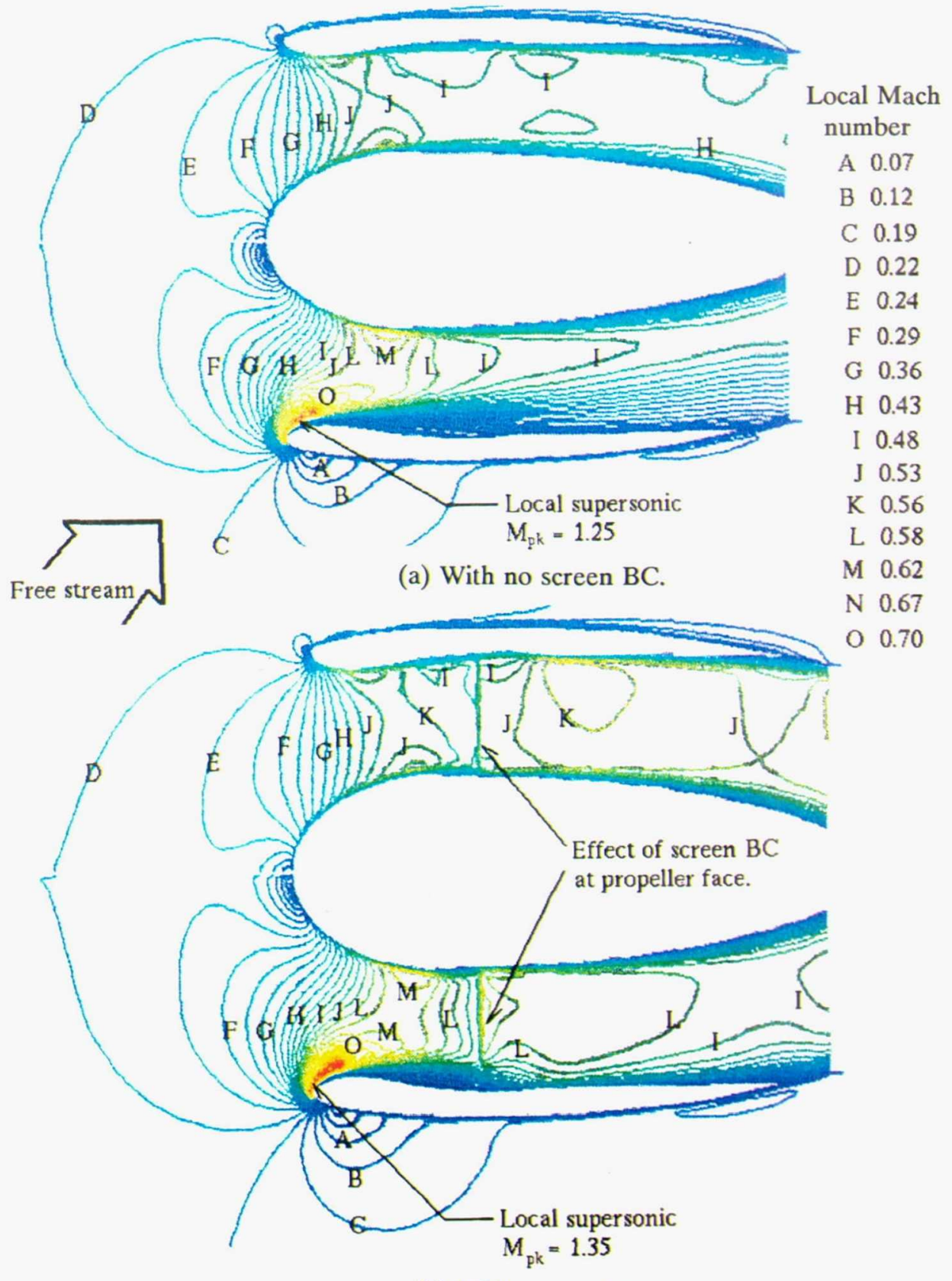

(b) With screen BC.

Figure 16. Mach contours over the inlet center plane for $\mathrm{M}_{0}=0.2, \alpha=29^{\circ}$, and $\mathrm{W}_{\mathrm{c}}=21.12 \mathrm{~kg} / \mathrm{sec}$. 
Page intentionally left blank 


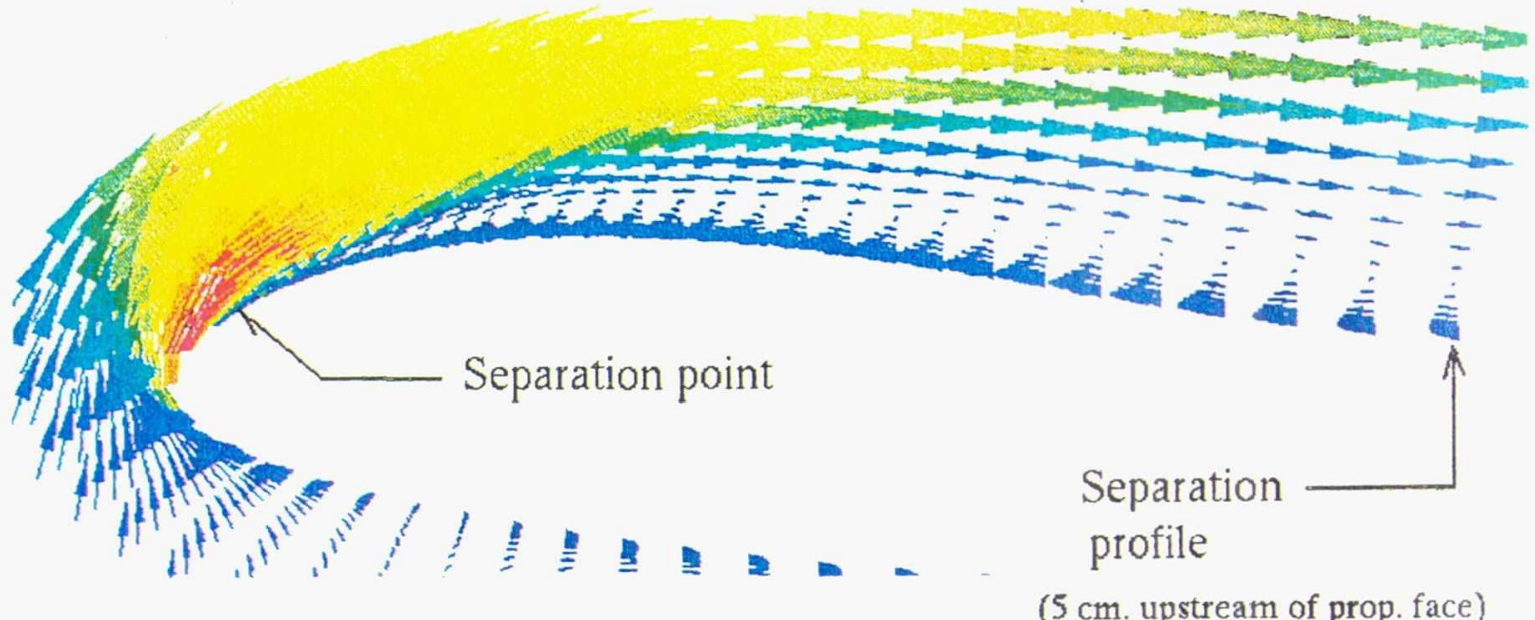

Without screen BC

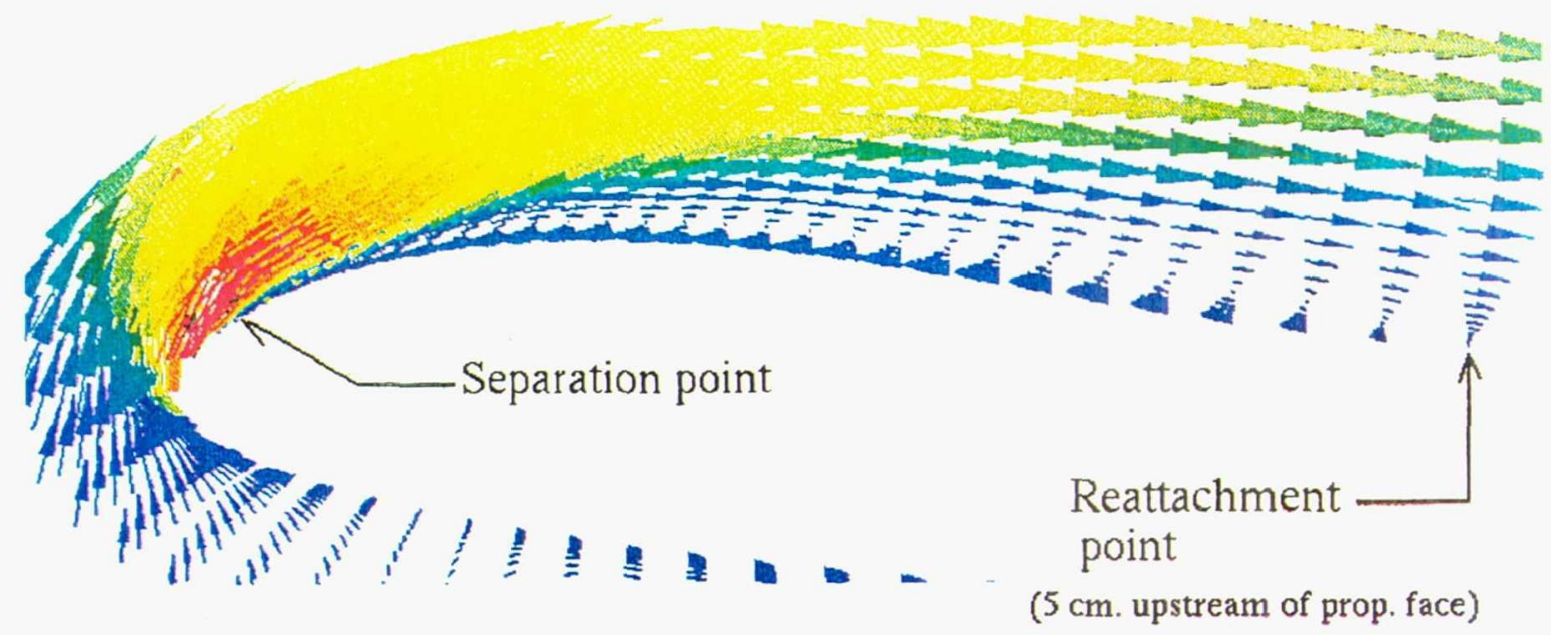

With screen $\mathrm{BC}$

(a) On the cowl windward side.

Figure 17. Axial velocity vector distributions for $\mathrm{M}_{0}=0.2, \alpha=29^{\circ}$, and $\mathrm{W}_{\mathrm{c}}=21.12 \mathrm{~kg} / \mathrm{sec}$. 
Page intentionally left blank 


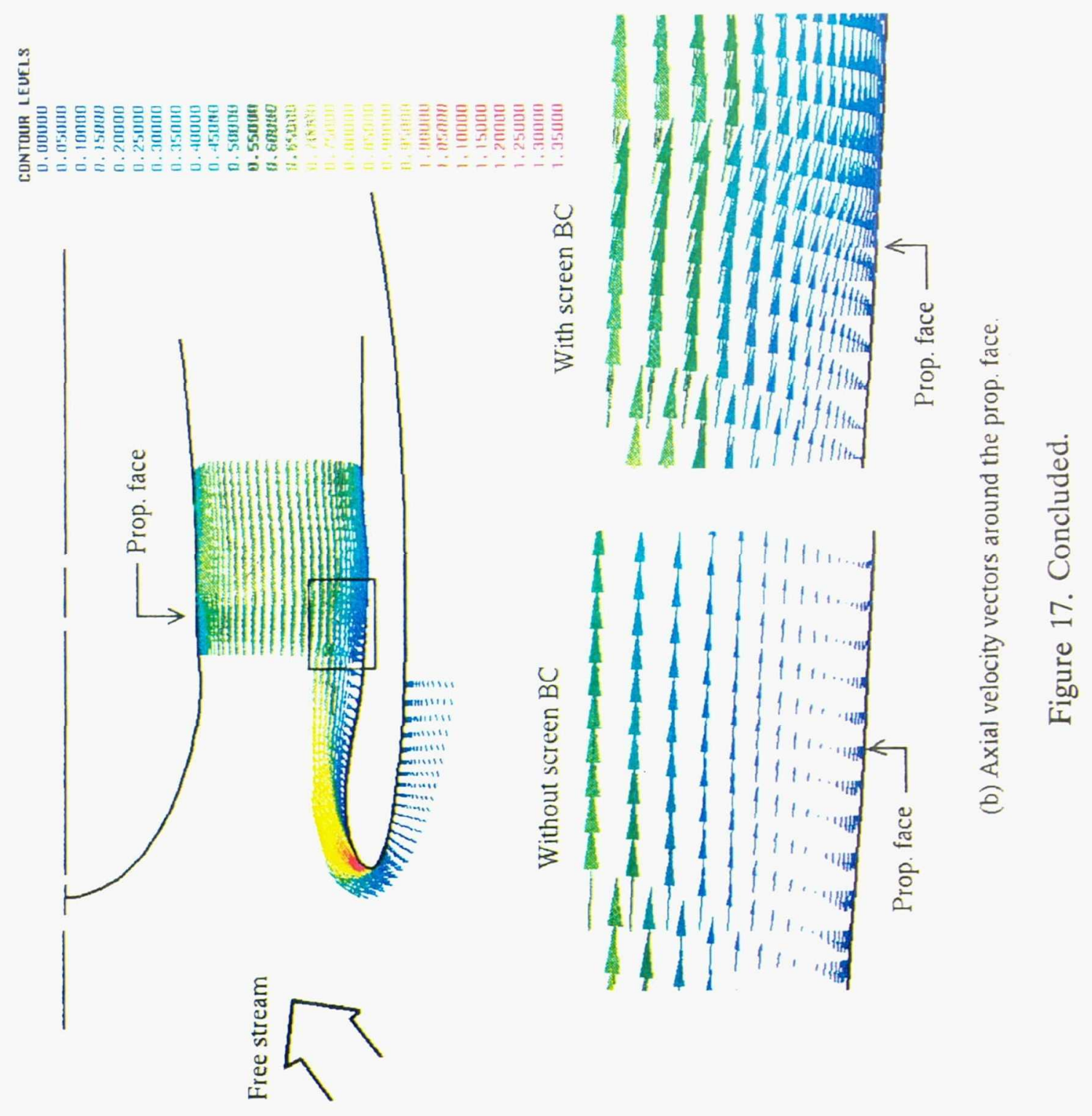


Page intentionally left blank 


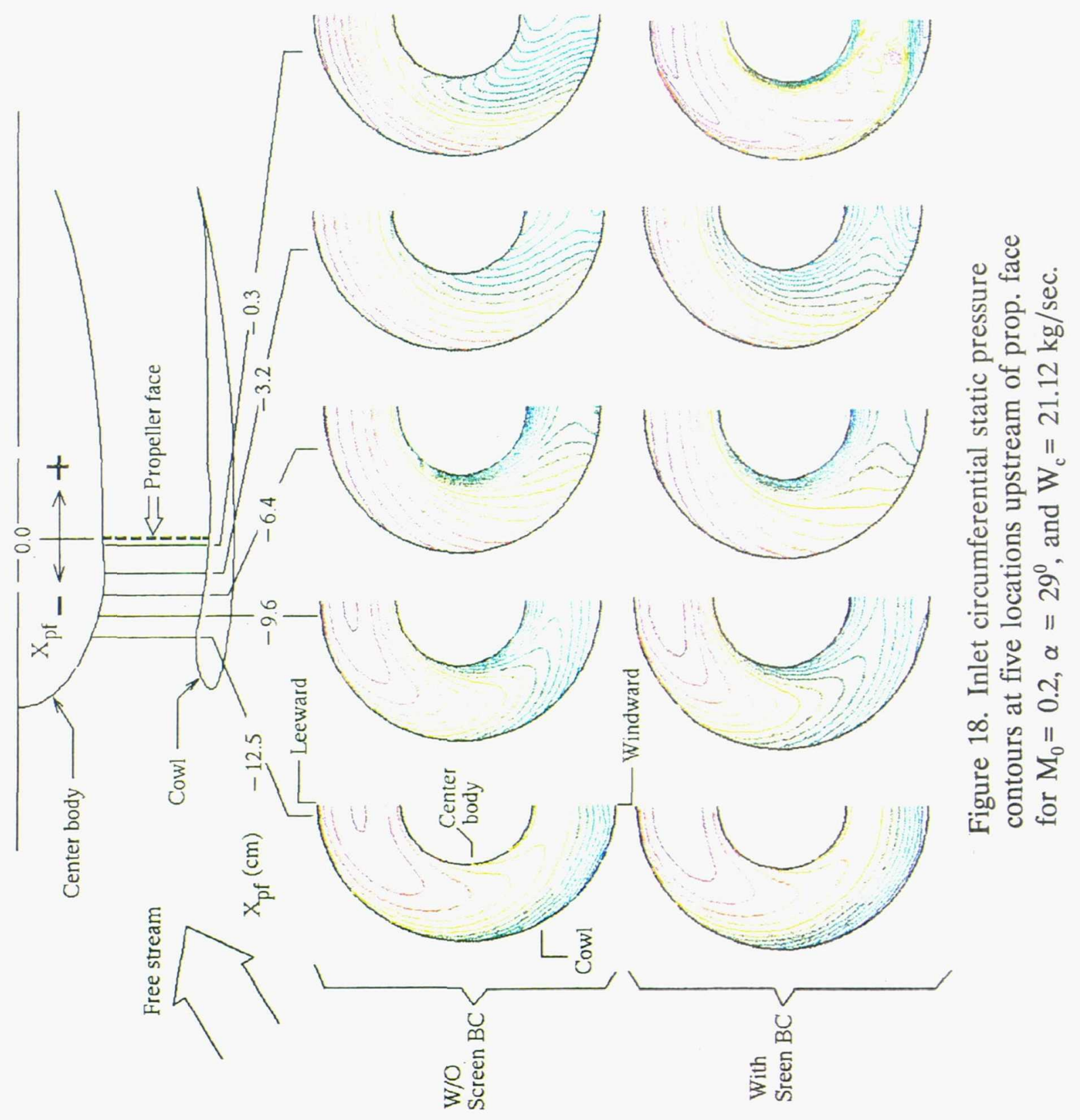


Page intentionally left blank 

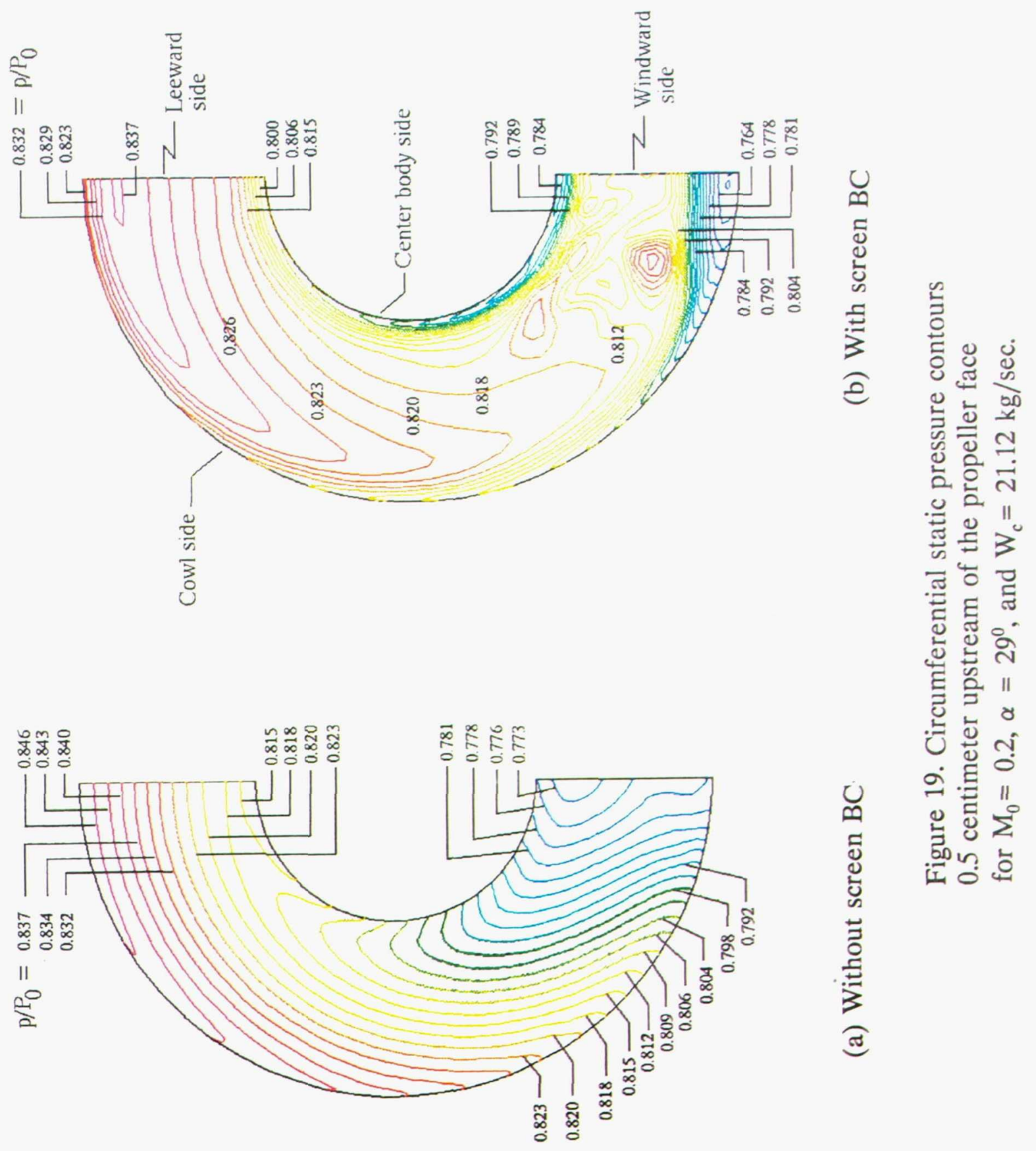
Page intentionally left blank 


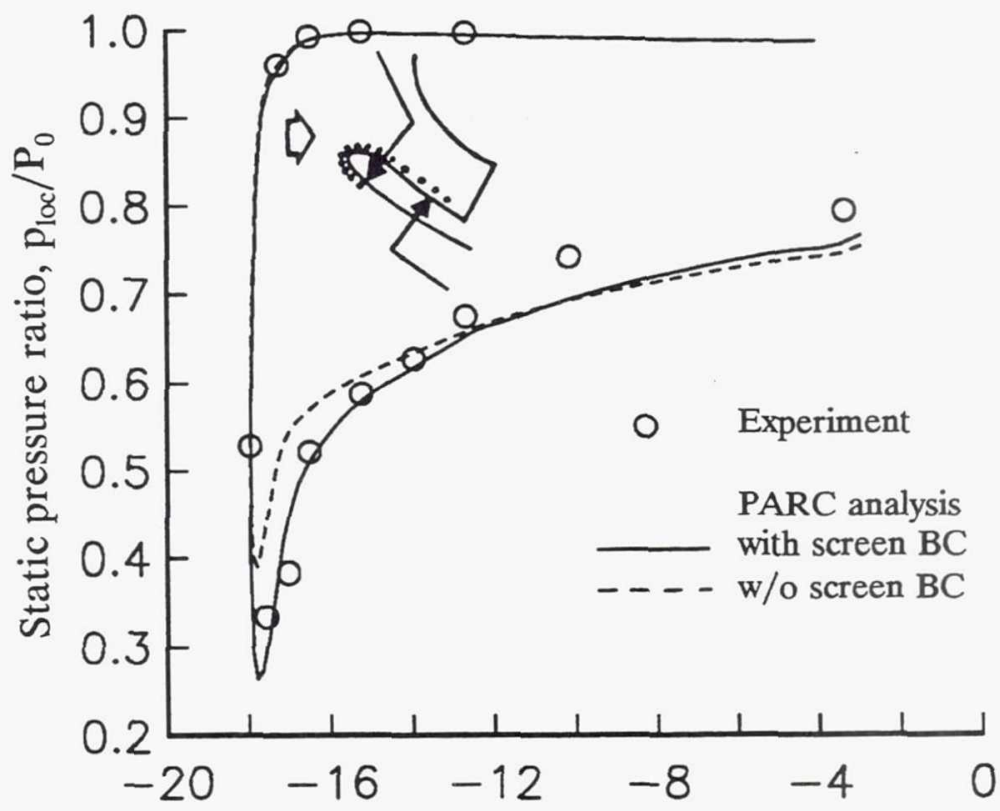

(a) Windward side, $\phi=0^{\circ}$

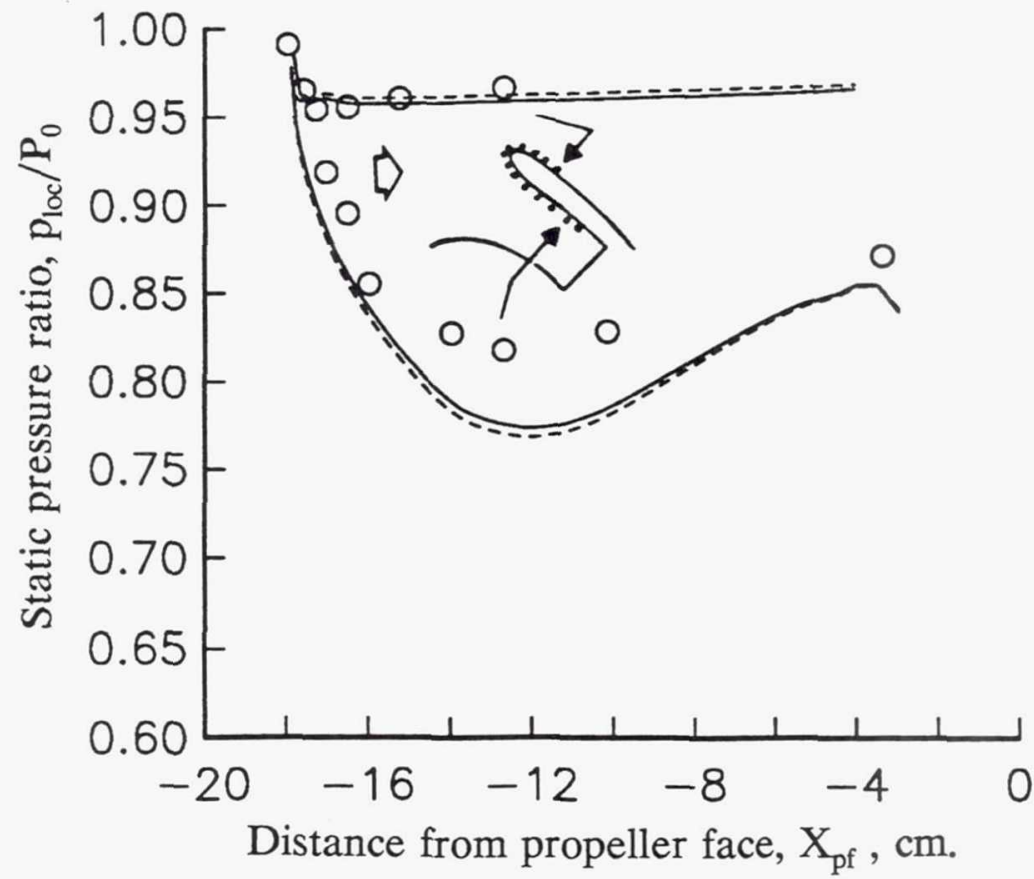

(b) Leeward side, $\phi=0^{\circ}$

Figure 20. Comparison of cowl static pressure distributions between analysis and ADP experiment for $\mathrm{M}_{0}=0.2, \alpha=29^{\circ}$, and $\mathrm{W}_{\mathrm{c}}=21.12 \mathrm{~kg} / \mathrm{sec}$. 


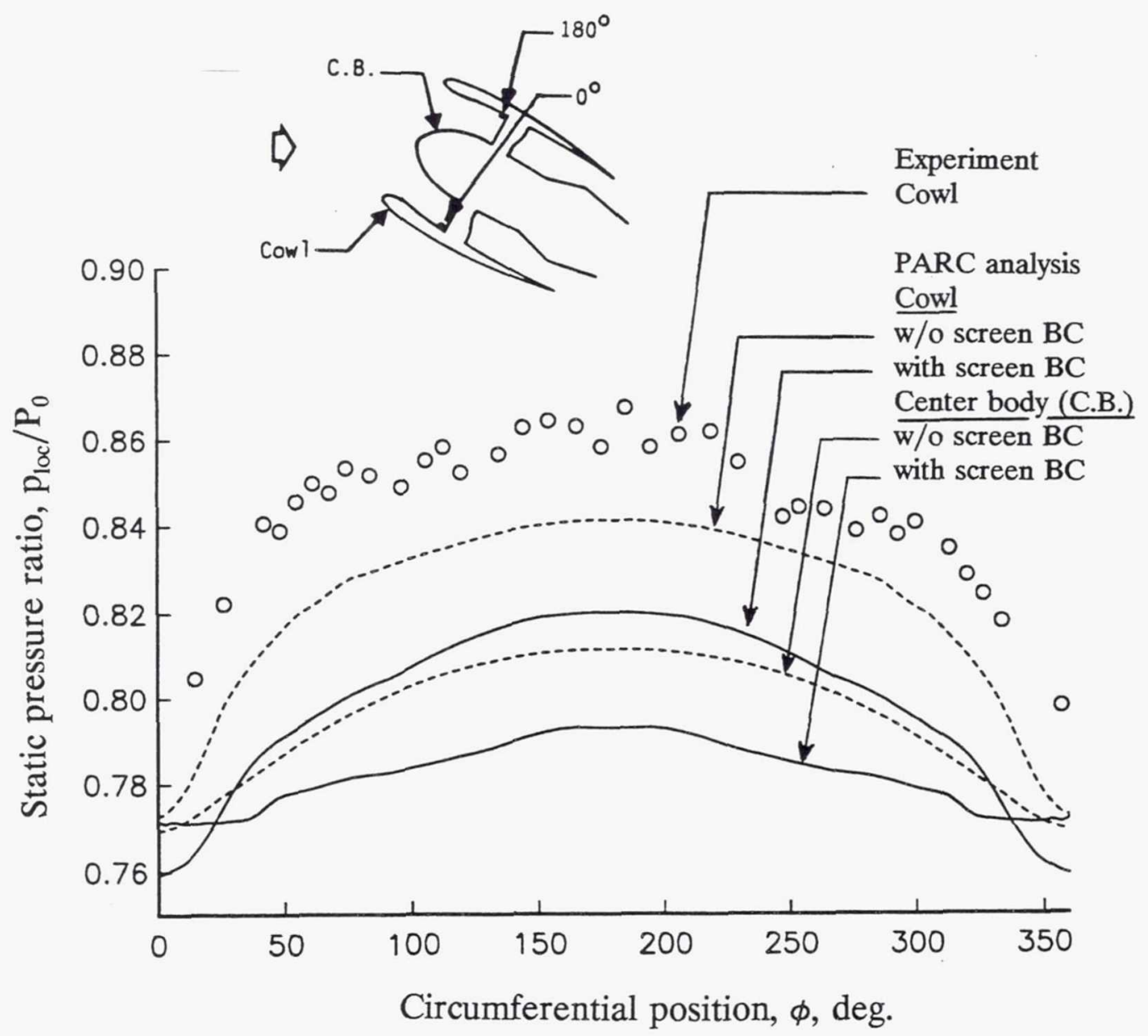

Figure 21. Comparison of circumferential static pressure distributions 0.5 centimeter upstream of propeller face for $\mathrm{M}_{0}=0.2, \alpha=29^{\circ}$, and $\mathrm{W}_{\mathrm{c}}=21.12 \mathrm{~kg} / \mathrm{sec}$. 
Local Mach number
A 0.07
H 0.43
B 0.12
I 0.48
C 0.19
J 0.53
D 0.22
E 0.24
K 0.56
F 0.29
L 0.58
G 0.36
M 0.62
N 0.67
O 0.70

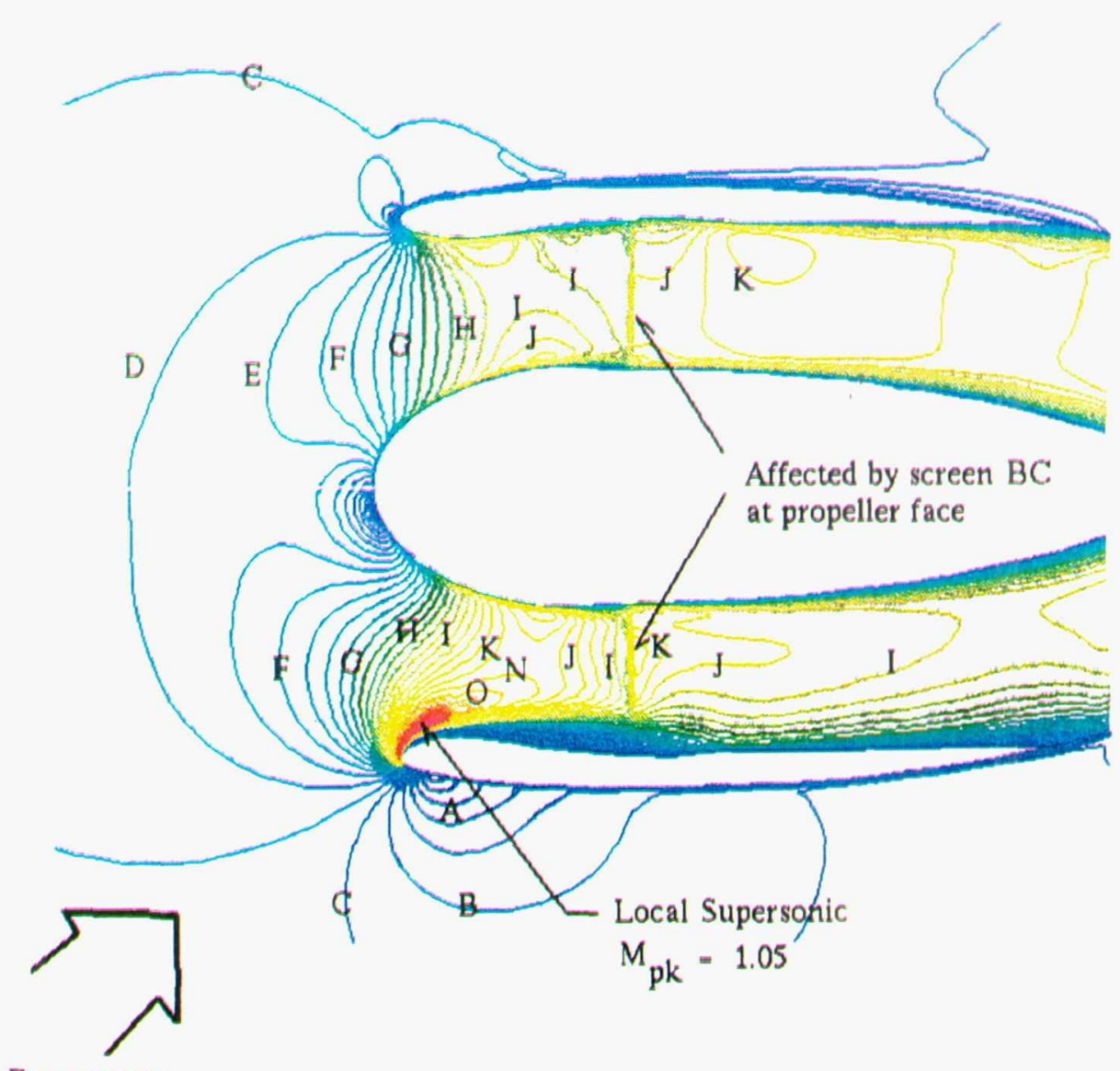

Free stream

Figure 22. Mach contours over the inlet center plane for $\mathrm{M}_{0}=0.2, \alpha=30^{\circ}$, and $\mathrm{W}_{\mathrm{c}}=21.12 \mathrm{~kg} / \mathrm{sec}$. 
Page intentionally left blank 


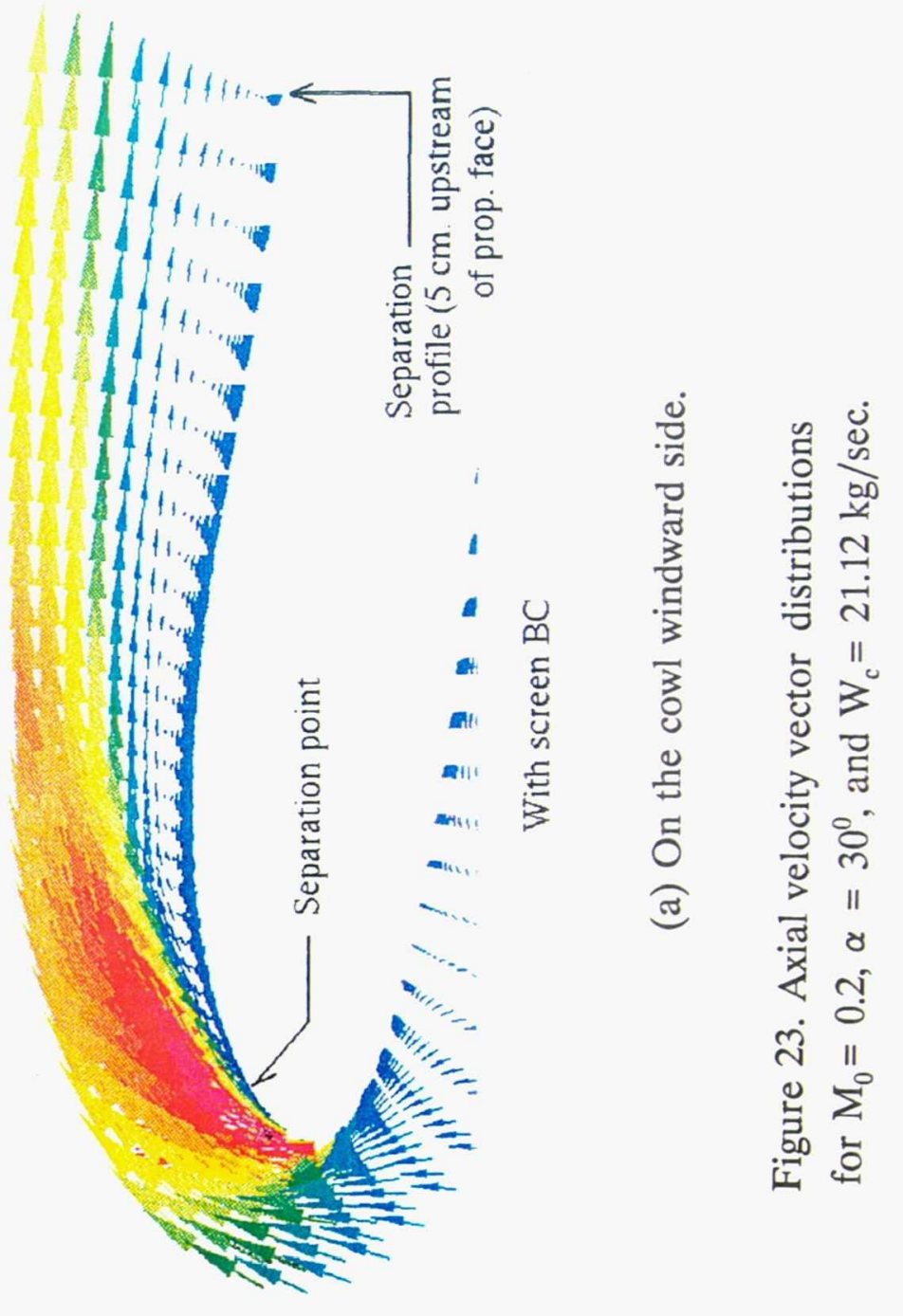


Page intentionally left blank 


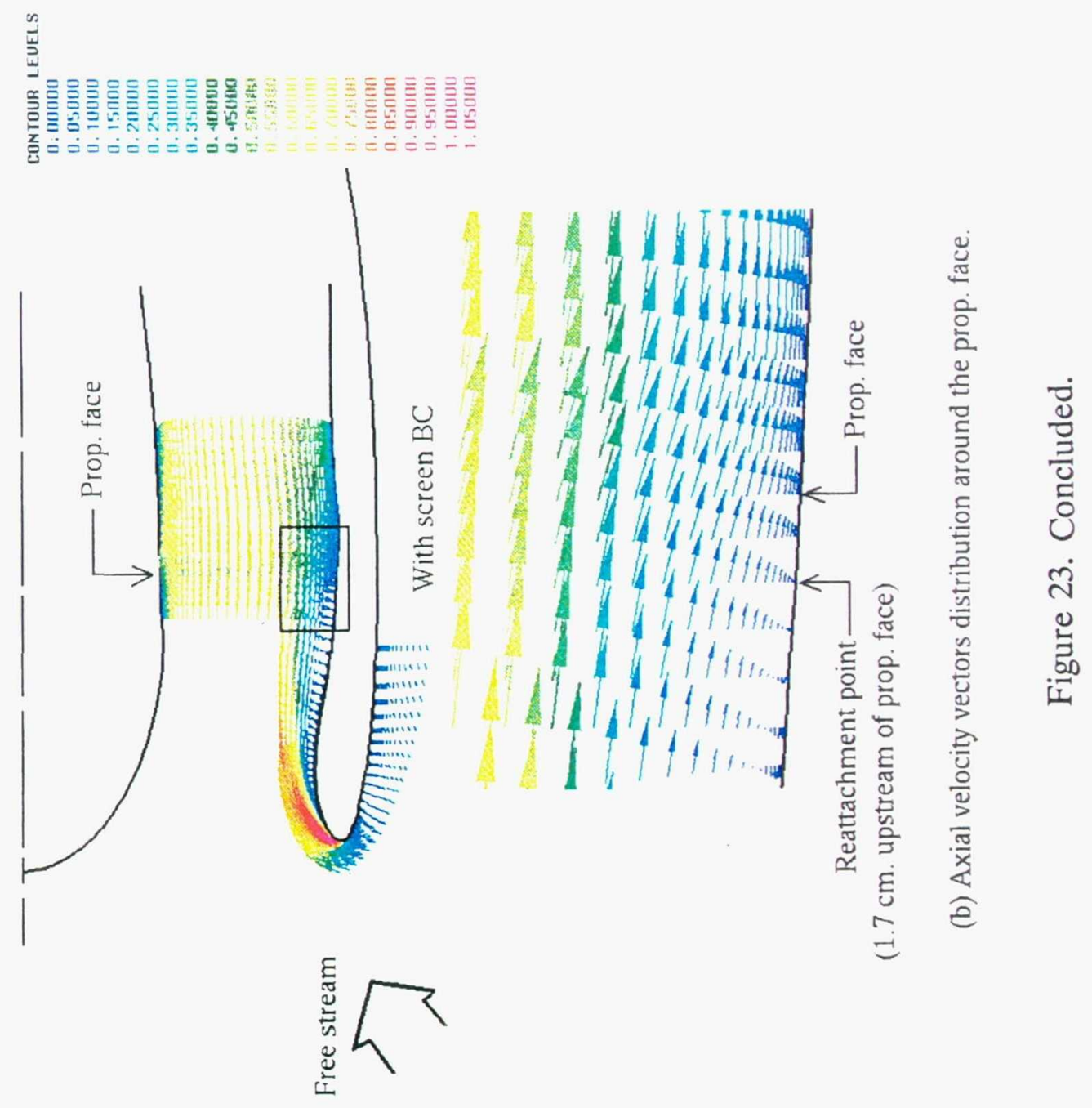


Page intentionally left blank 


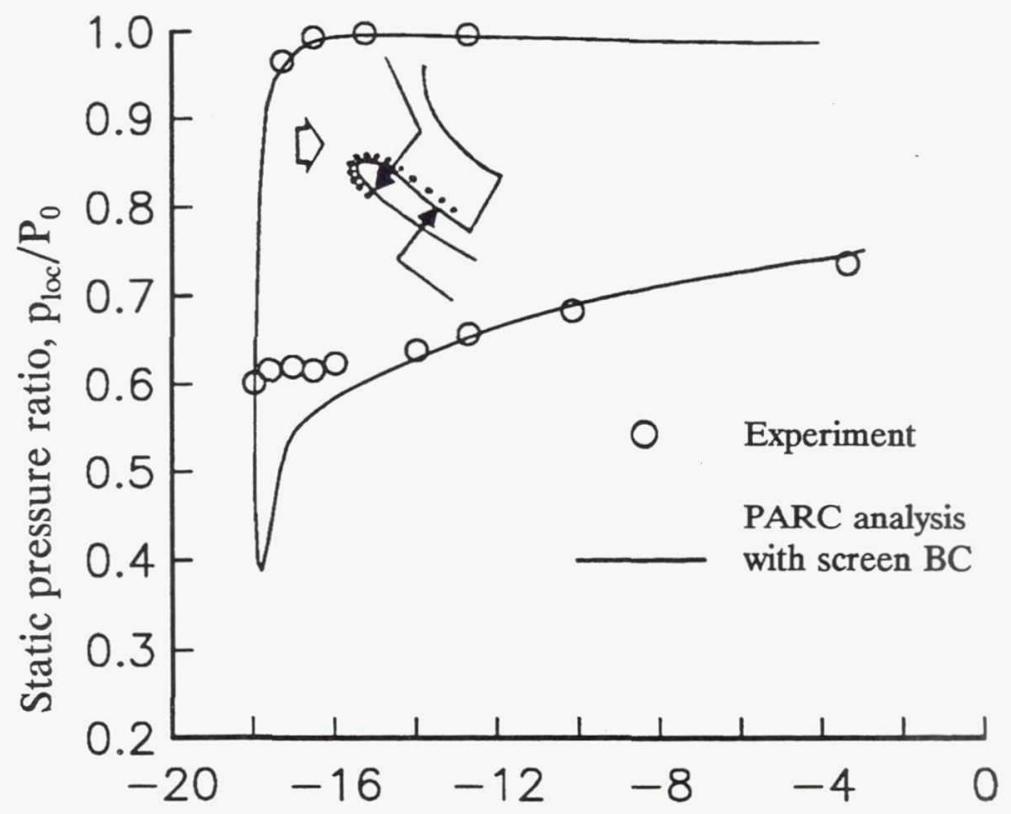

(a) Windward side, $\phi=0^{\circ}$

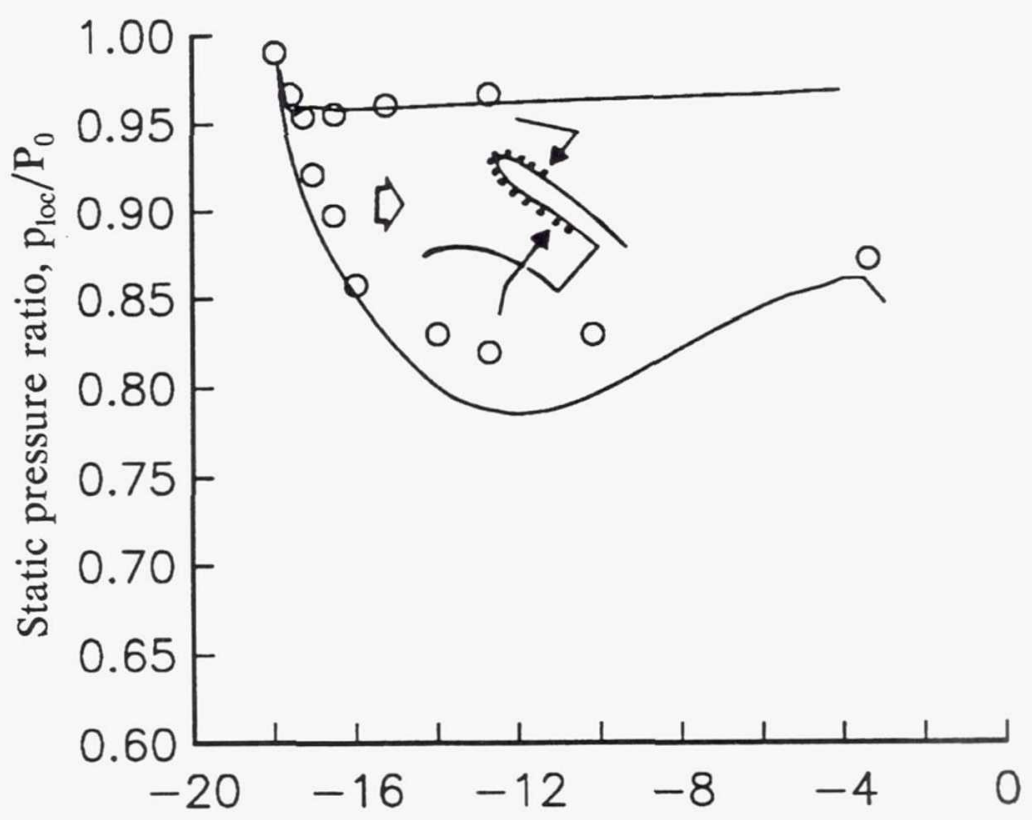

Distance from propeller face, $X_{\mathrm{pf}}, \mathrm{cm}$.

(b) Leeward side, $\phi=0^{\circ}$

Figure 24. Comparison of circumferential static pressure distributions 0.5 centimeter upstream of propeller face for $\mathrm{M}_{0}=0.2, \alpha=30^{\circ}$, and $\mathrm{W}_{\mathrm{c}}=21.12 \mathrm{~kg} / \mathrm{sec}$. 


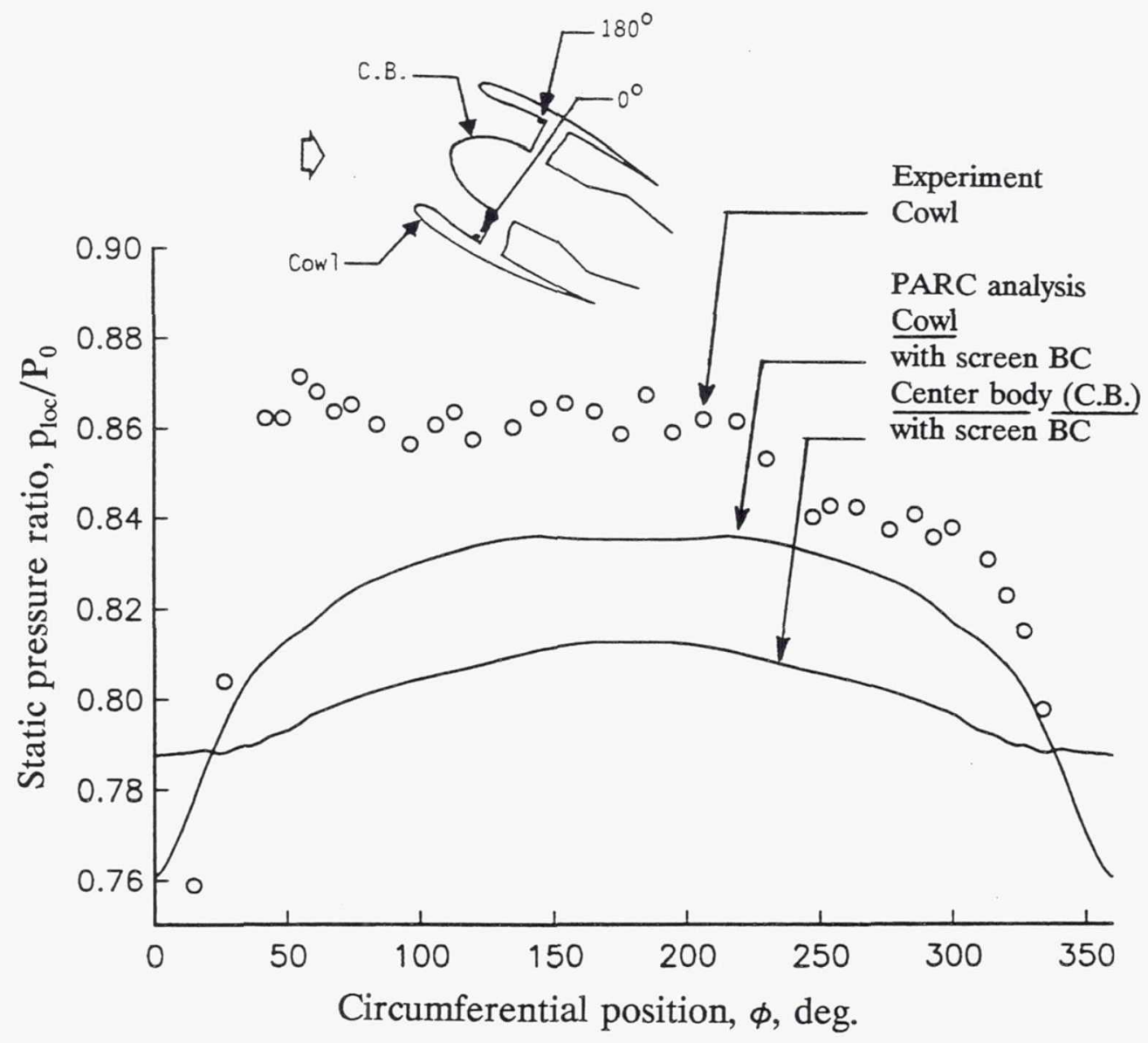

Figure 25. Comparison of circumferential static pressure distributions 0.5 centimeter upstream of propeller face for $\mathrm{M}_{0}=0.2, \alpha=30^{\circ}$, and $\mathrm{W}_{\mathrm{c}}=21.12 \mathrm{~kg} / \mathrm{sec}$. 
Public reporting burden for this collection of information is estimated to average 1 hour per response, including the time for reviewing instructions, searching existing data sources, gathering and maintaining the data needed, and completing and reviewing the collection of information. Send comments regarding this burden estimate or any other aspect of this collection of information, including suggestions for reducing this burden, to Washington Headquarters Services, Directorate for Information Operations and Reports, 1215 Jefferson Davis Highway, Suite 1204, Arlington, VA 22202-4302, and to the Office of Management and Budget, Paperwork Reduction Project (0704-0188), Washington, DC 20503.

\begin{tabular}{|l|c|c|c|}
\hline 1. AGENCY USE ONLY (Leave blank) & $\begin{array}{c}\text { 2. REPORT DATE } \\
\text { June } 1993\end{array}$ & $\begin{array}{r}\text { 3. REPORT TYPE AND DATES COVERED } \\
\text { Technical Memorandum }\end{array}$ \\
\hline
\end{tabular}

\section{TITLE AND SUBTITLE}

3-D Viscous Flow CFD Analysis of the Propeller Effect on an Advanced Ducted Propeller Subsonic Inlet

6. AUTHOR(S)

Chanthy Iek, Donald R. Boldman, and Mounir Ibrahim

7. PERFORMING ORGANIZATION NAME(S) AND ADDRESS(ES)

National Aeronautics and Space Administration

Lewis Research Center

Cleveland, Ohio 44135-3191

\section{FUNDING NUMBERS}

WU-505-03-10
9. SPONSORING/MONITORING AGENCY NAME(S) AND ADDRESS(ES)

National Aeronautics and Space Administration

Washington, D.C. 20546-0001
8. PERFORMING ORGANIZATION REPORT NUMBER

E-7958

10. SPONSORING/MONITORING AGENCY REPORT NUMBER

NASA TM-106240

AIAA-93-1847

\section{SUPPLEMENTARY NOTES}

Prepared for the 29th Joint Propulsion Conference and Exhibit cosponsored by the AIAA, SAE, ASME, and ASEE, Monterey, California, June 28-30, 1993. Chanthy Iek and Donald R. Boldman, NASA Lewis Research Center; and Mounir Ibrahim, Cleveland State University, Cleveland, Ohio 44115. Responsible person, Chanthy Iek, (216) 433-3897.

12a. DISTRIBUTION/AVAILABILITY STATEMENT

12b. DISTRIBUTION CODE

Unclassified - Unlimited

Subject Category 07

\section{ABSTRACT (Maximum 200 words)}

A time marching Navier-Stokes code called PARC3D was used to study the 3-D viscous flow associated with an advanced ducted propeller (ADP) subsonic inlet at take-off operating conditions. At a free stream Mach number of 0.2 , experimental data for the inlet-with-propeller test model indicated that the airflow was attached on the cowl windward lip at an angle of attack of $25^{\circ}$, became unstable at $29^{\circ}$, and separated at $30^{\circ}$. An experimental study with a similar inlet and with no propeller (through-flow) indicated that flow separation occurred at an angle of attack a few degrees below the value observed when the inlet was tested with the propeller. This tends to indicate that the propeller exerts a favorable effect on the inlet performance. During the through-flow experiment a stationary blockage device was used to successfully simulate the propeller effect on the inlet flow field at angles of attack. In the present numerical study, this flow blockage was modeled via a PARC3D computational boundary condition (BC) called the screen BC. The principle formulation of this $\mathrm{BC}$ was based on the one-and-half dimension actuator disk theory. This screen $\mathrm{BC}$ was applied at the inlet propeller face station of the computational grid. Numerical results were obtained with and without the screen BC. The application of the screen $\mathrm{BC}$ in this numerical study provided results which are similar to the results of past experimental efforts in which either the blockage device or the propeller was used.

\section{SUBJECT TERMS}

Computational fluid dynamics; Navier-Stokes; Actuator disk theory; Shrouded propeller; Engine inlets; Boundary layer separation

\begin{tabular}{l|c}
\hline 17. SECURITY CLASSIFICATION \\
OF REPORT \\
$\begin{array}{c}\text { Unclassified } \\
\text { 18. SECURITY CLASSIFICATION } \\
\text { OF THIS PAGE } \\
\text { Unclassified }\end{array}$
\end{tabular}

\section{SECURITY CLASSIFICATION} OF ABSTRACT Unclassified
15. NUMBER OF PAGES 61

16. PRICE CODE A04 20. LIMITATION OF ABSTRACT 
National Aeronautics and Space Administration

Lewis Research Center

Cleveland, Ohio 44135

Orficial Busines:

Penatty for Privete Uae $\$ 200$
FOURTH CLASS MAIL

ADDRESS CORRECTION REQUESTED 